\title{
THE URBAN BOUNDARY-LAYER FIELD CAMPAIGN IN MARSEILLE (UBL/CLU-ESCOMPTE): SET-UP AND FIRST RESULTS
}

P. G. MESTAYER, ${ }^{1, *}$ P. DURAND ${ }^{2}$, P. AUGUSTIN ${ }^{14}$, S. BASTIN $^{6}$, J. -M. BONNEFOND ${ }^{11}$, B. BÉNECH ${ }^{3}$, B. CAMPISTRON ${ }^{3}$, A. COPPALLE $^{4}$, H. DELBARRE ${ }^{14}$, B. DOUSSET ${ }^{5}$, P. DROBINSKI ${ }^{6}$, A. DRUILHET $^{3}$, E. FRÉJAFON ${ }^{15}$, C. S. B. GRIMMOND ${ }^{7}$, D. GROLEAU ${ }^{8}$, M. IRVINE ${ }^{11}$, C. KERGOMARD ${ }^{9}$, S. KERMADI ${ }^{10}$, J. -P. LAGOUARDE ${ }^{11}$, A. LEMONSU ${ }^{2}$,

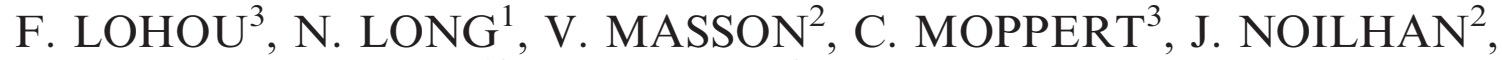
B. OFFERLE ${ }^{7}$, T. R. OKE ${ }^{12}$, G. PIGEON ${ }^{2}$, V. PUYGRENIER ${ }^{3}$, S. ROBERTS $^{12}$, J. -M. ROSANT ${ }^{1}$, F. SAÏD ${ }^{3}$, J. SALMOND ${ }^{12}$, M. TALBAUT ${ }^{4}$ and J. VOOGT VOG $^{14}$ ${ }^{1}$ Laboratoire de Mécanique des Fluides, CNRS - Ecole Centrale de Nantes, France; ${ }^{2}$ Centre National de Recherches Météorologiques, CNRS-Météo-France, Toulouse, France; ${ }^{3}$ Laboratoire d'Aérologie, OMP - UPS, Toulouse, France; ${ }^{4}$ CORIA CNRS - Université-INSA de Rouen, France; ${ }^{5}$ Laboratoire Géomer, CNRS - UBO, Brest, France and University of Hawaii, Honolulu, U.S.A.; ${ }^{6}$ Service d'Aéronomie, IPSL, Paris, France; ${ }^{7}$ Indiana University, Bloomington, U.S.A.; ${ }^{8}$ Laboratoire CERMA CNRS - École d'Architecture de Nantes, France;

${ }^{9}$ Laboratoire de Géographie des Milieux Anthropisés, Université des Sciences et Technologies de Lille, France; ${ }^{10}$ ESO, CNRS - Université du Maine, Le Mans, France; ${ }^{11}$ Unité de Bioclimatologie, INRA, Villenave d'Ornon, France; ${ }^{12}$ University of British Columbia, Vancouver, Canada; ${ }^{13}$ University of Western Ontario, London, Canada; ${ }^{14}$ Laboratoire de Physico-Chimie de l'Atmosphère, CNRS - Université du Littoral, France; ${ }^{15}$ INERIS, Verneuil en Halatte, France

\begin{abstract}
The UBL/CLU (urban boundary layer/couche limite urbaine) observation and modelling campaign is a side-project of the regional photochemistry campaign ESCOMPTE. UBL/CLU focuses on the dynamics and thermodynamics of the urban boundary layer of Marseille, on the Mediterranean coast of France. The objective of UBL/CLU is to document the four-dimensional structure of the urban boundary layer and its relation to the heat and moisture exchanges between the urban canopy and the atmosphere during periods of low wind conditions, from June 4 to July 16, 2001. The project took advantage of the comprehensive observational set-up of the ESCOMPTE campaign over the Berre-Marseille area, especially the ground-based remote sensing, airborne measurements, and the intensive documentation of the regional meteorology. Additional instrumentation was installed as part of UBL/CLU. Analysis objectives focus on (i) validation of several energy balance computational schemes such as LUMPS, TEB and SM2-U, (ii) ground truth and urban canopy signatures suitable for the estimation of urban albedos and aerodynamic surface temperatures from satellite data, (iii) high resolution mapping of urban land cover, land-use and aerodynamic parameters used in UBL models, and (iv) testing the ability of high resolution atmospheric models to simulate the structure of the UBL during land and sea breezes, and the related transport and diffusion of pollutants over different districts of the city. This paper presents initial results from such analyses and details of the overall experimental set-up.
\end{abstract}

* E-mail: Patrice.Mestayer@ec-nantes.fr 
Keywords: Energy balance, Mapping land cover, Radiative fluxes, Thermal remote sensing, Turbulent fluxes, Urban boundary layer, Urban meteorology.

\section{Introduction}

The assessment of air quality within an urban area requires that numerical models be able to simulate pollutant transport-diffusion and chemical transformations with fine spatial and temporal resolution, finer than the scale of the districts themselves. High resolution atmospheric boundary-layer models, in turn, require dedicated urban schemes and pre-processors, due to the special characteristics of the urban environment: artificial surface materials, anthropogenic sources of heat and water, and the presence of buildings. Together the building and vegetation elements found in cities form an open 'canopy' layer where airflow is channelled and flow re-circulation is common, where solar radiation is trapped due to multiple reflections between vertical and horizontal surfaces, and the escape of infrared radiation to the sky is hindered. In addition, the building surfaces themselves are heterogeneous, comprising a large range of materials with different radiative, thermodynamic and roughness properties. Furthermore, building-atmosphere exchanges are affected by the ventilation, heating, and air-conditioning systems of the buildings.

Two converging co-operative research efforts were launched in France in 2000, focused on the dynamics and thermodynamics of the urban atmosphere: UBL/CLU (CLU, couche limite urbaine, translates to urban boundary layer, and TUE (the French acronym for environmental urban remote sensing). The purpose of the TUE program is the assessment of methods and algorithms to derive parameters and data needed as inputs for urban atmospheric models from remote sensing data. TUE aims to address simultaneously both the development of physical models to predict urban canopy responses to shortwave and longwave radiation, and algorithms to evaluate surface and canopy parameters from satellite data. Initial efforts focus on the ability to use the visible, near infrared (NIR), and thermal infrared (TIR) wavebands to determine urban land cover, structure, surface albedo, surface temperature, and the convective sensible heat flux. This dovetails nicely with recent initiatives to model the urban energy balance: the physically-based Town Energy Balance scheme (TEB) of Masson (2000), the Local-Scale Urban Meteorological Parameterisation Scheme (LUMPS) of Grimmond and Oke (2002), and the Sub-Meso Soil Model - Urban (SM2-U) of Dupont et al. (2000). The CLU program aims to improve understanding of interactions between the lower atmosphere and urban systems, to better specify the vertical structure of the urban atmospheric boundary layer and its relation to city structure and meteorological conditions, and to further develop and evaluate models and algorithms to simulate the urban atmosphere at high spatial resolution. In 
addition to the urban schemes already noted, these include the French mesoscale models Meso-NH (Lafore et al., 1998) and SUBMESO (Mestayer, 1996; Anquetin et al., 1999), their sub-models, and pre-processors.

The ESCOMPTE campaign is part of a continuing coordinated effort to support the development of urban pollution models, focused mainly on the understanding and prediction of photochemical episodes (ESCOMPTE is the French acronym for a field experiment to constrain the models of pollution emission transport). The ESCOMPTE aims to construct a reference data base for model validation, based on an extensive regional emissions inventory, a dense permanent air quality monitoring network, and an experimental campaign, in a region with episodes of high peak ozone pollution (Cros et al., 2004; medias.obs-mip.fr/escompte). The field campaign was run from June 4 to July 16, 2001, in the Provence region of southern France. In addition to permanent pollution networks, about thirty ground- or sea-based stations, and six airborne platforms to document the chemistry and transport of the emitted gaseous and particle pollutants, of ozone, its precursors and by-products, were implemented. Taking advantage of this opportunity, UBL/CLU sought to document the urban boundary layer of Marseille during periods of high insolation and low wind conditions characteristic of land/sea-breeze regimes.

Apart from the field studies at the scale of a street or a few buildings for air quality and comfort purposes (for example, Vachon et al., 2002), previous urban observation projects usually consist of either 'point' assessments of the energy balance at the local scale of select land use categories, or evaluations of the meteorological influence of an urban area at the mesoscale (e.g. the urban 'plume'). These experiments and their relation to model validation have been reviewed by, for example, Oke (1987, 1998), Mestayer and Anquetin (1994), Mestayer (1998), Rotach et al. (2002), Grimmond and Oke (2002), Piringer et al. (2002) and Arnfield (2003). The aim of the UBL/CLU project is to integrate climatological and meteorological experimental approaches at multiple scales. In particular it seeks to document urban energy exchanges and impacts on the atmosphere at scales extending from those of the urban canopy layer up to the scale of the city. This was achieved by complementing the ESCOMPTE regional field program with an assessment of the three-dimensional structure and time evolution of wind, temperature and humidity fields, especially the UBL depth, surface temperatures and energy balance fluxes at the urban surface and near the top of the UBL. The project had four principal objectives: (i) to evaluate existing urban energy flux schemes, (ii) to test/validate algorithms to compute the urban albedo, surface temperature and convective sensible heat flux using satellite data, (iii) to evaluate the ability of high resolution atmospheric models to simulate the urban boundary layer, and (iv) to provide reference datasets of the dynamic fields and diurnal cycles for further studies of urban atmospheric physics and chemistry (Mestayer and Durand, 2002). 
The present paper describes first the nature of the Marseille area using detailed mapping analyses (Section 2), the experimental set-up (Section 3 and Table I) and instrument intercomparisons (Section 4). This is followed by overviews of the objectives, experimental rationale, measurement details and preliminary results of each of the field project facets: the surface energy balance of the city centre (Section 5), the variability of air temperature and humidity in the urban canopy (Section 6), the three-dimensional (3-D) structure of the UBL documented by airborne and ground-based remote sensing systems (Section 7), and the visible and thermal infrared measurements from ground, aircraft and satellites (Section 8).

\section{Marseille Area}

Marseille is located on the Mediterranean coast in an arena of hills rising to 400-650 $\mathrm{m}$ above sea level (asl); between the hills small valleys converge towards the ancient harbour 'Vieux Port' and the Prado beach, which are themselves separated by a steep hill about $200 \mathrm{~m}$ high. The city faces the sea on the west (Figure 1), in the southern part of a large bay (scale of $\approx 100 \mathrm{~km}$ ), with the sea to the south-south-west. This combination of orientations is important when analysing sea-breeze episodes as well as when the weather is dominated by the mistral (the wind exiting from the Rhone valley in the north and turning towards the east when reaching the coast).

\subsection{Surface Database}

Numerical databases necessary for the calculation of aerodynamic and thermodynamic features of urban areas for use in planning field projects, or as input to models, rarely exist with sufficient detail. In this project, two methods have been used in parallel to obtain geo-referenced databases of surface materials and morphology: firstly, high resolution satellite observations, and secondly, urban and geographic elevation databases.

\subsubsection{SPOT 4 Image Analyses}

Two multi-spectral and panchromatic images obtained from Spot 4 on June 17, 2000 have been analysed to map the surface cover of the city. The two sets of data were combined, the image re-sampled at a resolution of $10 \mathrm{~m}$ and a site-adapted classification was created. This involved the use of numerical masks and the creation of two classifications; the first from the multi-spectral data for 'built/mineral' surfaces (rocks, bare soil, pavement, roofs); the second for vegetated surfaces based on the Normalized Differential Vegetation Index (NDVI) and Soil Adjusted Vegetation Index (SAVI). The combined classifications were vectorized and integrated into a Geographical Informa- 


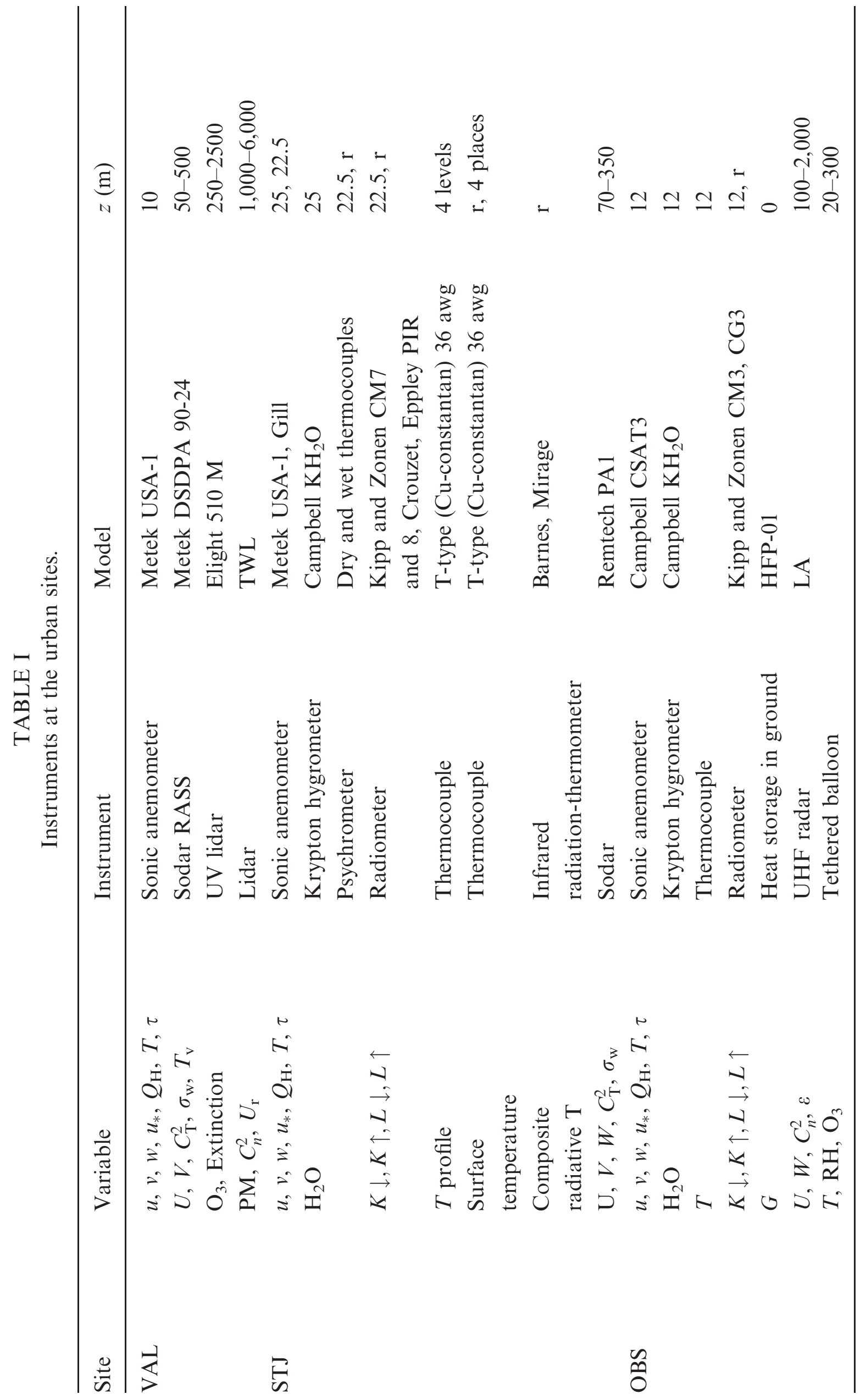




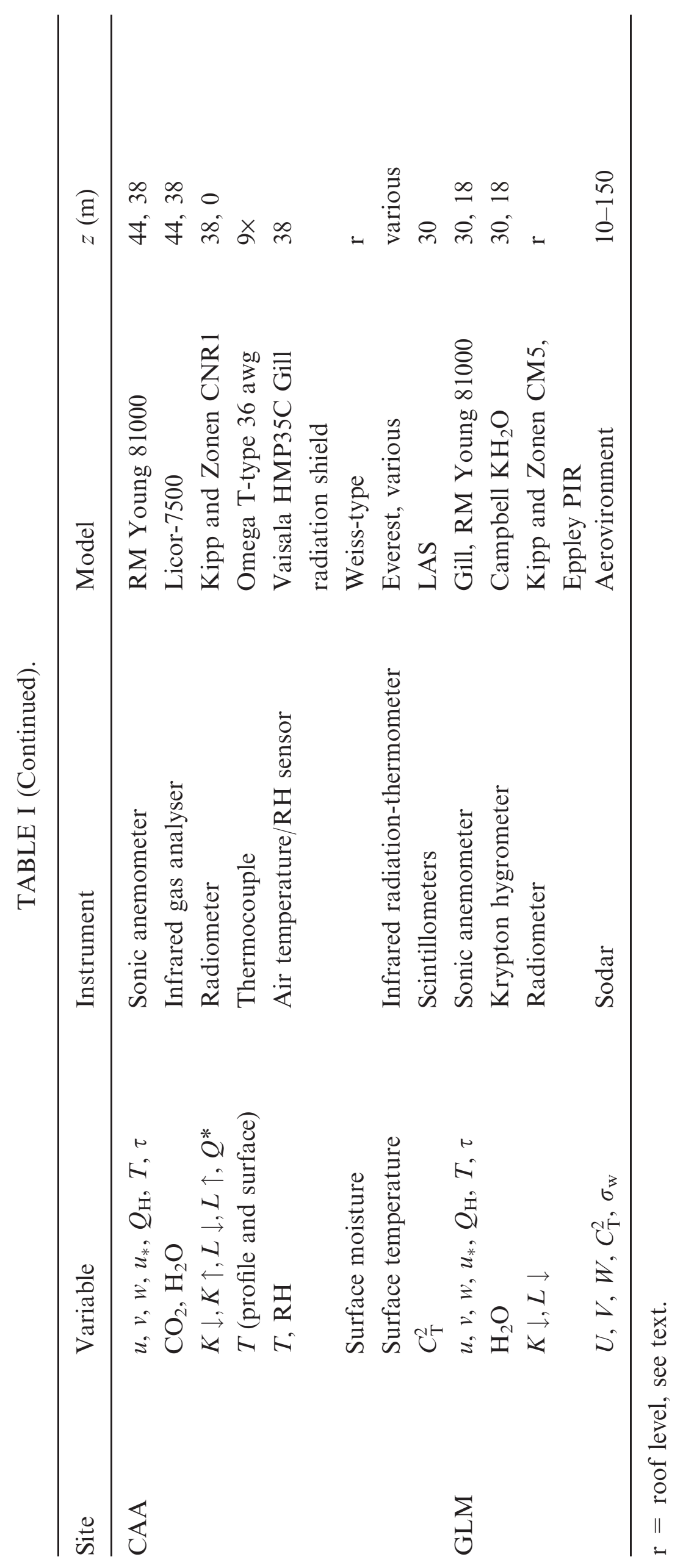




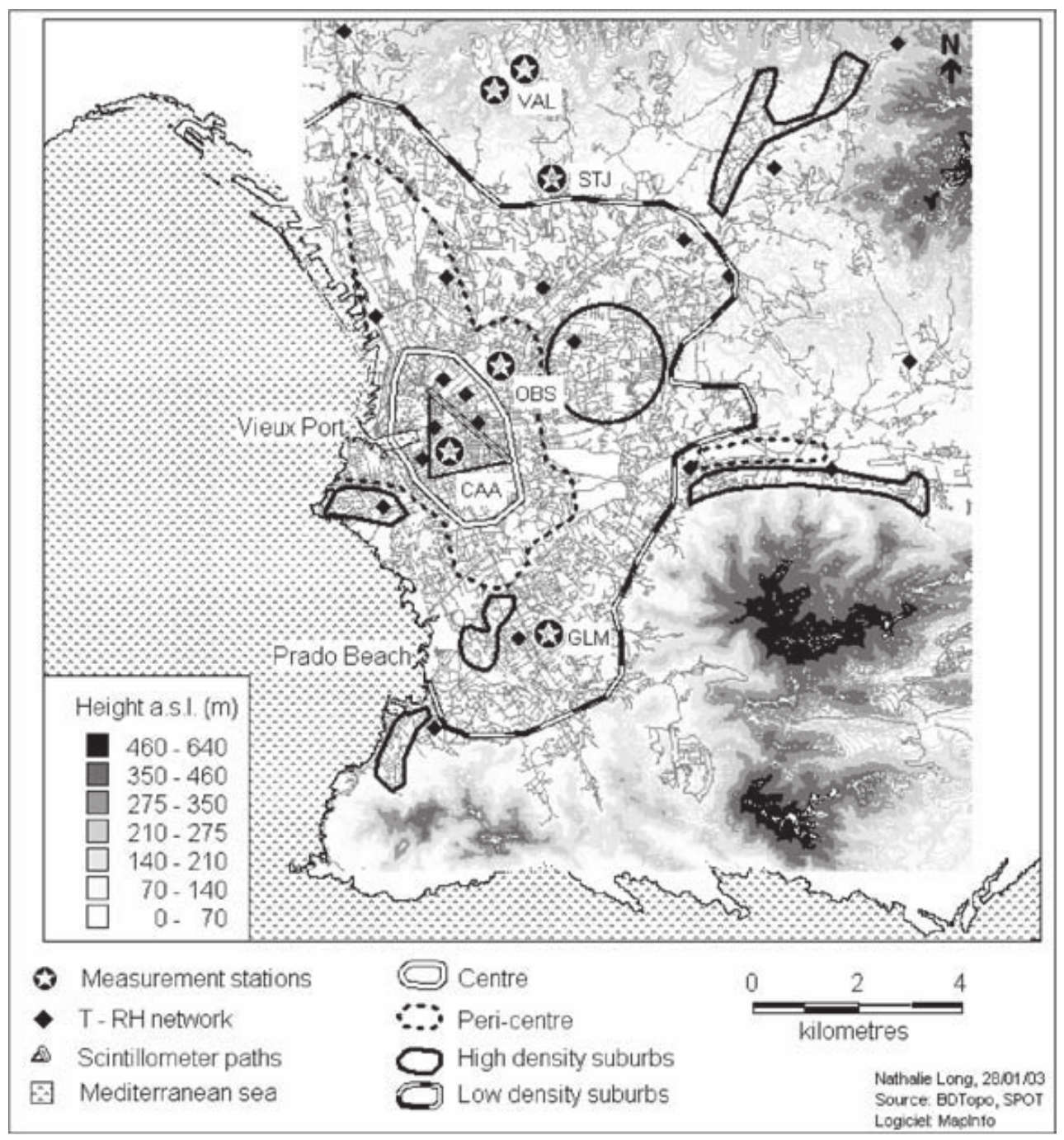

Figure 1. Map of Marseille city and its vicinity (analysed section of the BDTopo). The Etoile ridge lies immediately north of the map limit. The map indicates the limits of the main built-up area (Long, 2003), the stars - the positions of UBL/CLU measurement stations; the diamonds - the T-RH network, and the straight lines - the scintillometer paths.

tion System (GIS) (Figure 2). Some urban elements were difficult to distinguish from each other. For example, dense housing and industrial areas; herbaceous vegetation of the city edges and parks, gardens and lawns within the city; and bare soil, limestone hills or burned areas. This problem has been encountered in other urban areas (Armand, 1995). Results can be improved by the use of an image taken during the spring, when stronger contrasts between urban vegetation and surrounding mineral surfaces may be expected. The classification was used to create grids with $100-\mathrm{m}$ and $200-\mathrm{m}$ resolution of the percentage of each land cover class.

\subsubsection{BDTopo Analysis}

The BDTopo database of the French National Geographic Institute (IGN) contains information on ground cover, including different types of vegetation, buildings, the river and stream network, and the road/street network. 

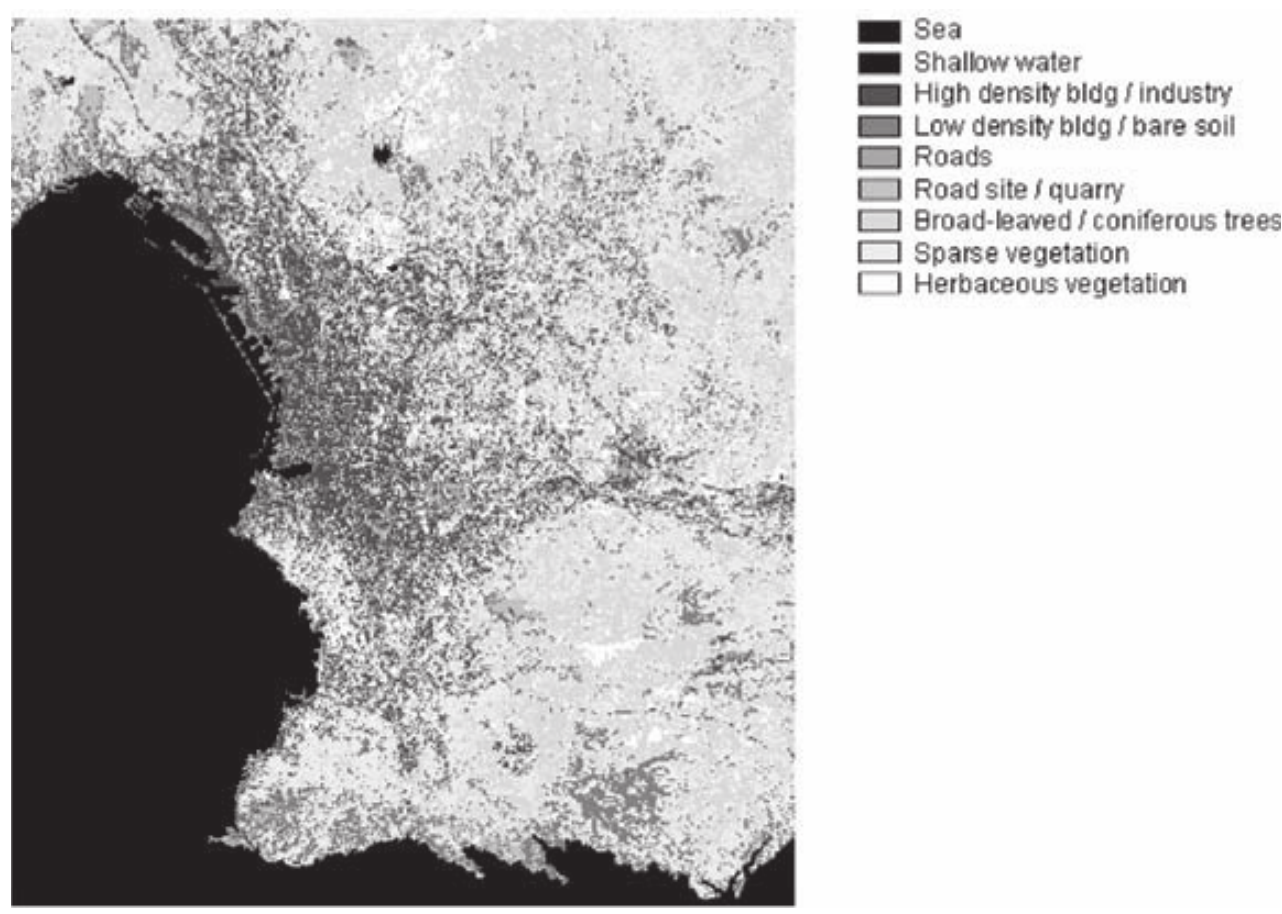

Figure 2. Land use in Marseille area derived from initial Spot 4 data analysis (no correction for vegetation cover).

Each element in the database is a polygon with geographic coordinates (Lambert III) and an accuracy $<1 \mathrm{~m}$. Topographic points/contours and altitudes of building roofs and tops of trees are included (Figure 1). DFMap software, developed by Long et al. (2002), was used to convert the vector data to raster and to compute spatial statistics such as average building heights (Figure 3), volumes, perimeters, compactness (the surface-to-perimeter ratio compared to that of a circle*), plan area fractions of buildings, vegetation, water bodies, and pavement, building number per cell $\left(40,000 \mathrm{~m}^{2}\right)$, mean street width, and aspect (street height:width) ratio. The roughness length and the zero-plane displacement height for momentum were calculated using the Raupach (1994), Bottema (1997) and Macdonald et al. (1998) methods with direction-dependent frontal and lateral surface indices. The cell size and model parameters can be chosen by the user.

\subsubsection{Marseille Area Analysis}

Initial comparisons between the data within BDTopo, the cadastral database of the City's geographic and environmental service, the Spot satellite images and the derived maps of urban land cover properties demonstrate several limitations for each approach (Long et al., 2003a). For example, BDTopo strongly underestimates the vegetation cover in the city centre.

* Compactness $C=\left(S_{\mathrm{c}} / P_{\mathrm{c}}\right) /\left(S_{\mathrm{b}} / P_{\mathrm{b}}\right)$, with $S_{\mathrm{c}}=S_{\mathrm{b}}$, where $S$ is surface and $P$ perimeter, and where indices $\mathrm{c}$ and $\mathrm{b}$ indicate circle and building. 


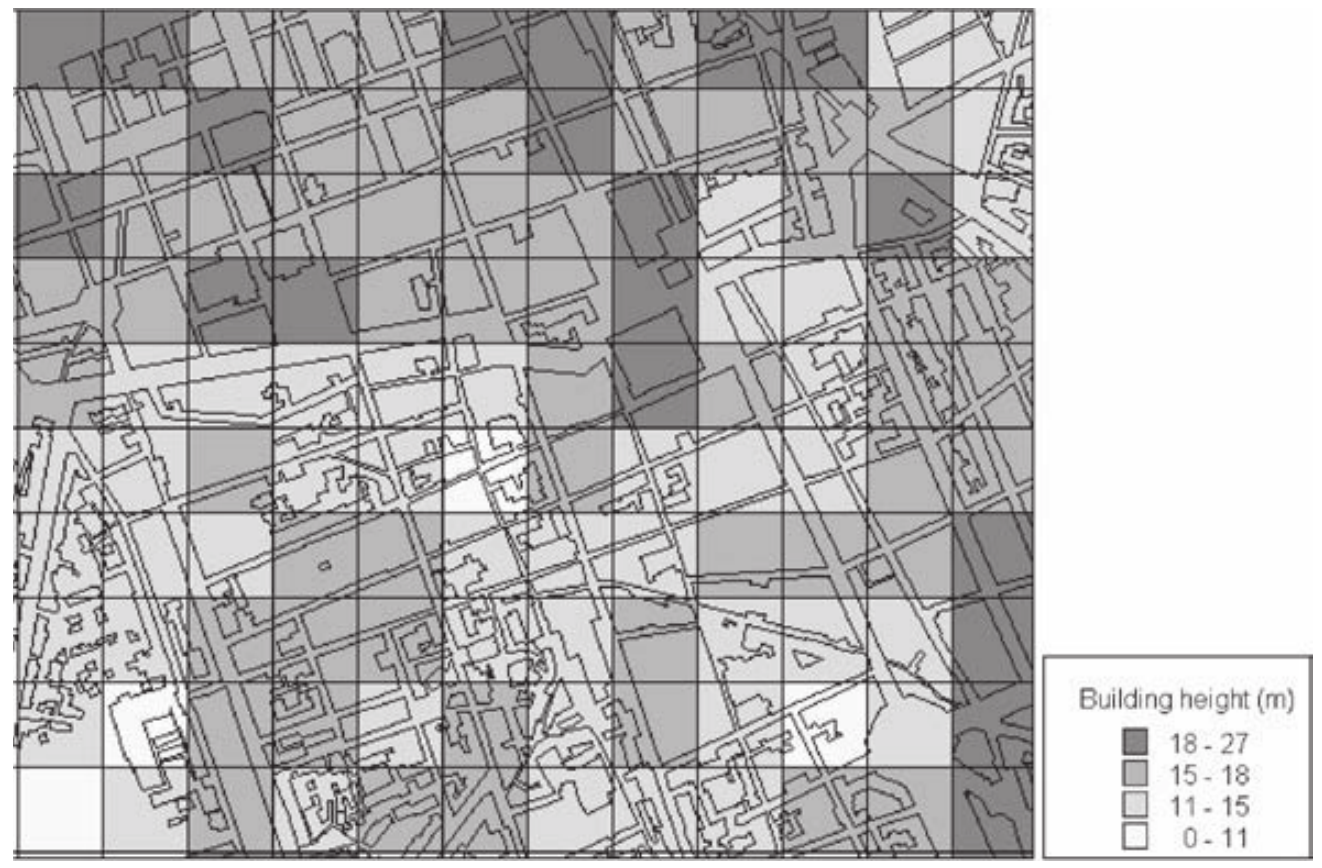

Figure 3. Average building heights $(\mathrm{m})$ in the city centre around the CAA site, as computed with DFMap. Here the grid size is $100 \mathrm{~m}$, showing artificial variability due to a too small number of buildings per grid cell.

The minimum cell size having both aerodynamic and statistical significances has been shown to be $\approx 200 \mathrm{~m}$ (Long, 2003). A $k$-means automatic classification (nuées dynamiques, Diday et al., 1982) of the urban fabric based on 10 morphological and land cover parameters (see above) obtained with DFMap were used to classify the urban area into relatively homogeneous areas from both morphologic and aerodynamic viewpoints. Nine district types were identified: centre (Figure 1), pericentre (Figure 1), i.e., the quarters immediately around the centre with mostly 3-storey row buildings and long industrial buildings, residential buildings, small residential buildings, high density individual housing (Figure 1), low density individual housing (Figure 1), sparse individual housing, residual individual housing, and the big buildings. This last district type covers only eight cells with atypical buildings.

The population of the metropolitan area is about one million. Except in the city centre, the harbour area and the outskirts of the city, buildings are most often composed of a mix of single or row houses and small ensembles of 4- to 10 -story apartment buildings. In the city centre, roughly within a circle $2 \mathrm{~km}$ in radius around the Vieux Port, the street pattern is relatively regular and the buildings form a dense canopy averaging $15 \mathrm{~m}$ in height, with a few higher, isolated buildings (centre in Figure 1). Around the harbour is a $0.5-$ to $1-\mathrm{km}$ wide strip of relatively low warehouse and industrial buildings and large open paved surfaces that extend along the coast north of Vieux Port (pericentre in Figure 1). The outskirts of the city are mainly composed of individual houses with gardens, of varying density, in relatively small lots spread over the hill 
slopes (high density suburbs and low density suburbs in Figure 1). The whole area is interspersed with small groups of large residential buildings (blocks of flats). The city contains few isolated high-rise towers.

\section{Experimental Set-Up}

\subsection{Surface-Layer measurements in the urban AReA}

In the urban area, five stations were equipped with micrometeorological masts, aligned along a north-south axis, roughly parallel to the shoreline (indicated with stars in Figure 1). Continuous measurements of radiation and turbulent fluxes necessary to monitor the local-scale surface energy balance were made at three urban stations GLM, CAA and STJ. At these sites masts extended 12-25 $\mathrm{m}$ above the top of the urban canopy and turbulent fluxes were measured at two levels (Section 4).

The central site (CAA) was located in the 19th century portion of the city centre that is relatively and uniformly dense (Grimmond et al., 2002); a telescoping mast was installed on the roof of the Cour d'Appel Administrative (CAA) $\left(43.29^{\circ} \mathrm{N}, 5.38^{\circ} \mathrm{E}, 13 \mathrm{~m}\right.$ asl). Details of the sensors and measurement heights are given in Sections 4 and 5 and Table I. This site was also equipped with an array of up to 19 infrared radiation thermometers (IRTs), either fixed to monitor the surface temperature of selected surface elements, or hand-held to evaluate surface temperature distributions within street canyons during intense observation periods (Roberts et al., 2003). Air temperature differences between the interior and exterior of buildings during some periods were also monitored.

Two large aperture scintillometers (LAS) were installed over the city centre between June 12 and July 10; each is of $0.152 \mathrm{~m}$ diameter and operates at $0.93 \mu \mathrm{m}$. Transmitters and receivers were placed on the terraces of three buildings (Paradis, Nedelec and Timone Hospital) giving path lengths of 1785, 1878 (black straight lines in Figure 1) and $2308 \mathrm{~m}$ (double line in Figure 1). The average height of the optical beam above the estimated zero-plane displacement height was about $30 \mathrm{~m}$ (Irvine et al., 2002; Lagouarde et al., 2002b).

The STJ station was located at the Technical University Institute (IUT) St Jérôme $\left(43.34^{\circ} \mathrm{N}, 5.41^{\circ} \mathrm{E}, 130 \mathrm{~m}\right.$ asl), in a heterogeneous suburban area comprising a mixture of small individual villas with gardens and 4-storey apartment houses. Within an approximate $1 \mathrm{~km}$ radius of the tower the mean building height is $6.6 \mathrm{~m}$ with a standard deviation of $4.8 \mathrm{~m}$. In the southern sector (university campus) and the northern direction, building heights vary between 13 and $17 \mathrm{~m}$, while to the west there was no building within $500 \mathrm{~m}$ of the station. The building plan area density was low, about $0.1-0.2$, except in the northern direction (maximum of 0.58 ) and immediately 
to the west $0.35-0.4$. The turbulence flux sensors (Table I) were mounted at two levels on a 12-m mast, installed on the flat roof of a 13-m high building, with the upper level at the top of the mast and the other $2.5 \mathrm{~m}$ lower. Two IRTs monitored the composite surface temperatures immediately north and south of the site.

The GLM site was located $2.5 \mathrm{~km}$ east of the sea in the southern part of the city, in the grounds of a research campus $\left(43.25^{\circ} \mathrm{N}, 5.40^{\circ} \mathrm{E}, 32 \mathrm{~m}\right.$ asl). The immediate neighbourhood is mainly residential, including tall buildings, with moderate plan area densities; the mean building height is $10.5 \mathrm{~m}$ with a standard deviation of $7.5 \mathrm{~m}$. A $30-\mathrm{m}$ pneumatic tower was installed on the ground between buildings (Coppalle and Talbaut, 2002), and was equipped at two-levels, at the top of the mast and at $18 \mathrm{~m}$ above ground level (agl).

The Observatoire site (OBS) $\left(43.30^{\circ} \mathrm{N}, 5.39^{\circ} \mathrm{E}, 70 \mathrm{~m}\right.$ asl) was located in the observatory gardens on the hill of the Palais Longchamp park and zoo, $2 \mathrm{~km}$ north-east of the CAA site. To the west and north is the main train station with large sheds and workshops. In the other directions there were residential areas similar to those in the city centre at the central site (CAA). Within about $1 \mathrm{~km}$ of the station the mean building height was about $11.4 \mathrm{~m}$ with a standard deviation of $4.7 \mathrm{~m}$. The turbulence sensors were mounted on a 10-m high mast erected on a grass site at the top of the hill.

The northern station Vallon Dol (VAL) $\left(43.36^{\circ} \mathrm{N}, 5.40^{\circ} \mathrm{E}, 285 \mathrm{~m}\right.$ asl) was located at the edge of the urban area, $2.5 \mathrm{~km}$ further north from the STJ station, in the vicinity of a small water reservoir $450 \mathrm{~m}$ in diameter (220 $\mathrm{m}$ asl). The terrain slopes upward to the Etoile ridge, with an average slope of $15 \%$. Except for a dense housing estate located about $0.7 \mathrm{~km}$ to the south-east, and a scattered settlement to the south, the area around the site is covered with sparse scrubland. Flux measurements were obtained using a 3-D sonic anemometer at the top of a 10-m mast.

The spatial and temporal structure of the air temperature and moisture fields in the canopy layer were documented with a network of 20 automatic stations (T-RH network). Air temperature and moisture were recorded every 10 min using platinum resistance thermometers for air temperature, and capacitance probes for moisture. The instruments were installed in meteorological shields on 2-m horizontal booms fixed to street light poles, generally at a height of approximately $2 / 3$ of the mean surrounding building height.

\subsection{Ground-BASEd Vertical PROFILE MEASUREMENTS}

The two suburban sites (STJ and GLM) were equipped with Doppler sodars to measure the wind profile in the atmospheric surface layer (Coppalle and Talbaut, 2002). The OBS site hosted a wind profiler UHF radar, a tethered balloon that was used to measure thermodynamic and ozone profiles from 
20 to $300 \mathrm{~m}$ occasionally, and a radiosonde balloon-launching system. The VAL site included a RASS-sodar vertical sounder for temperature and wind components and two lidars that scanned horizontally and vertically out to a distance of about $10 \mathrm{~km}$ : a UV angular lidar (Elight, model $510 \mathrm{M}$ ) for ozone concentration, and a 10- $\mu \mathrm{m}$ Doppler lidar (called TWL, Transportable Wind Lidar) for the radial wind component. Both lidars provided information on the aerosol content in the scanned volume, and were operated in parallel to generate tomographic observations of the urban boundary layer (Section 7).

\subsection{INTENSIVE OBSERVATIONAL PERIOD MEASUREMENTS}

Most of the above-mentioned measurements were recorded continuously during the six weeks of the campaign, with the exception of the sodars that occasionally operated at reduced power during nights and week-ends, and the lidars and the tethered balloon that were mainly restricted to the intensive observation periods (IOPs).

During the campaign, two types of IOPs were conducted (Table II): (1) the five ESCOMPTE IOPs (called 1, 2a, 2b, 3 and 4, lasted a combined total of 15 days) during situations with land/sea breezes and high insolation, mixed with a light mistral during IOPs $2 \mathrm{a}$ and 4 . During these periods an airplane flew over Marseille, measuring the atmospheric composition and the wind and turbulence within or near the top of the boundary layer. IOP 3 was followed by a three-day period during which the atmospheric boundary layer (ABL) was also documented by the aircraft (ABL IOP); (2) the four thermal

TABLE II

Calendar of the UBL/CLU-ESCOMPTE campaign.

\begin{tabular}{ll}
\hline Events & Date (2001) \\
\hline Intercomparison & June $4-8$ \\
IOP 1 & June $14-15$ \\
IOP 2a & June $21-23$ \\
IOP 2b & June 23-26 \\
TIR day 1 & June 26 \\
TIR day 2 & June 30 \\
IOP 3 & July $2-4$ \\
ABL IOP & July 5-7 \\
IOP 4 & July $10-13$ \\
TIR day 3 & July 10 \\
TIR day 4 & July 12 \\
\hline
\end{tabular}


infrared (TIR) IOPs, when a light airplane equipped with a TIR scanner recorded images of the urban canopy at different times of the day.

The combined influence of the sensor viewing angles and the sun illumination geometry on the surface temperature measurements were documented by flying sequentially in eight different directions with respect to the sun over three typical areas of the city, including the city centre around the CAA site with its array of IRTs (Section 8). Radiosondes were launched from the OBS site during these IOPs, and air temperature was also monitored at the 2-m level with the 'T-RH Clio', a car equipped with shielded air temperature and humidity sensors at 2-m height, driven under the flight paths. During the light aircraft overflights, there was also additional sampling of surface temperatures in the downtown area using: (a) teams of observers equipped with hand-held IRTs who conducted detailed sampling of temperatures from building walls and streets; (b) a thermal scanner mounted on the roof of a tall building to sample detailed images of street-canyon temperatures (including some roof temperatures).

\subsection{Complementary datasets}

Satellite images from the observation period were collected from a variety of sensors and platforms (Section 8). A series of 159 images were acquired from the Advanced Very High Resolution Radiometer (AVHRR) on board satellites NOAA-12, NOAA-14 and NOAA-16, giving an average of four images per day, each with a resolution of $1.1 \mathrm{~km}$ in the visible, NIR and TIR wavebands. Sixty-six images from the MODIS sensor on board the TERRA satellite were also obtained from the NASA/EOSDIS data centre. In addition, the UBL/CLU dataset comprises the SPOT 4 multi-spectral and panchromatic images acquired during two flights, with a $15-\mathrm{m}$ resolution, and the 'physiographic' maps obtained from the analyses described in Section 2 (Long et al., 2002).

As a companion project, GPS-ESCOMPTE, a network of 18 Global Positioning System (GPS) receivers was deployed from June 6 to June 27 to continuously monitor the integrated depth of water vapour and the horizontal and vertical moisture gradients via a tomographic technique (Bock et al., 2004; Walpersdorf et al., 2004). Of the receiver array, 12 were located inside the Marseille urban area, and are used to describe the structure and evolution of the water vapour field in the urban boundary layer.

The UBL experimental set-up described here does not include pollutant chemistry measurements since they were part of the ESCOMPTE field campaign and are described elsewhere (Cros et al., 2004) All data obtained during the campaign are included in the ESCOMPTE comprehensive database, now freely accessible (medias.obs-mip.fr/escompte). 


\section{Data Quality Issues}

\subsection{INTERCOMPARISON OF FLUX INSTRUMENTS}

The deployment of multiple dynamic, thermodynamic and chemical sensors and analysers during the ESCOMPTE campaign necessitated careful attention to instrument intercomparison. Here we restrict consideration to the surface energy flux instruments deployed at twelve rural and urban surface stations. The intercomparison was conducted from June 5-7 at a site located in the semi-arid part of La Crau. This plain, west of Marseille $\left(43^{\circ} 34^{\prime} \mathrm{N}, 04^{\circ}\right.$ $49^{\prime} \mathrm{E}, 10 \mathrm{~m}$ asl), extends over more than $10^{8} \mathrm{~m}^{2}$ and consists of a flat, uniform, almost bare soil surface composed of clay and stones, with sparse grass. The site is characterized by a fetch greater than $1 \mathrm{~km}$ in all directions and a roughness length of about $0.015 \mathrm{~m}$. The wind blew from the south on June $5\left(180^{\circ}, 7 \mathrm{~m} \mathrm{~s}^{-1}\right)$ whereas the mistral prevailed on June $6\left(330^{\circ}, 8_{-}\right.$ $\left.9 \mathrm{~m} \mathrm{~s}^{-1}\right)$. The net radiation peaked between 500 and $600 \mathrm{~W} \mathrm{~m}^{-2}$ at noon on both days, being interrupted only by small fair weather cumuli.

Ten masts were installed on an area of about $10^{4} \mathrm{~m}^{2}$, with separations ranging from 20 to $100 \mathrm{~m}$ (Table III). Flux measurement at one station was based on the simplified aerodynamic method, whereas all the others used fast-response sensors $(10$ or $20 \mathrm{~Hz})$ and the eddy-covariance method. Eleven sonic anemometers from five different companies, one Li-cor 6262 and eight krypton $\mathrm{KH}_{2} \mathrm{O}$ hygrometers were operated during the comparison. Most of the sonic anemometers were mounted at 5-6 m agl, except for one at $2 \mathrm{~m}$ and one at $8 \mathrm{~m}$. Given the fetch and site character, these measurement heights should all lie in the constant flux layer.

Participating research groups analysed their own data using their own methods; all used 15-min block averages. Therefore, the following comparisons integrate the uncertainties of both measurement and data processing. The results presented here are restricted to the heat and moisture fluxes, $\overline{w^{\prime} T^{\prime}}$ and $\overline{w^{\prime} q^{\prime}}$, and the friction velocity $u_{*}=\left(-\overline{u^{\prime} w^{\prime}}\right)^{1 / 2}$, where $u^{\prime}, w^{\prime}, T^{\prime}$ and $q^{\prime}$ are the instantaneous deviations of the streamwise and vertical wind components $\left(\mathrm{m} \mathrm{s}^{-1}\right)$, temperature $\left({ }^{\circ} \mathrm{C}\right)$, and absolute humidity $\left(\mathrm{g} \mathrm{m}^{-3}\right)$, from their respective 15-min means. The temperature measured by the sonic anemometers is nearly the virtual temperature and requires correction for moisture influences; this could easily be performed when the specific humidity was also measured close by (Larsen et al., 1993), but unfortunately this was not available at some stations. However, given the low values of the moisture flux during these 2 days, the flux correction did not exceed $2 \%$, except when the sensible heat fluxes were very low. Therefore the results below are unlikely to be significantly affected. The mean parameters measured at $6 \mathrm{~m}$ agl have also been compared. The differences between the individual measurements and the averaged values of wind speed and tem- 
TABLE III

Research groups and sensors involved in the flux intercomparison (italics indicate stations that did not measure latent heat flux).

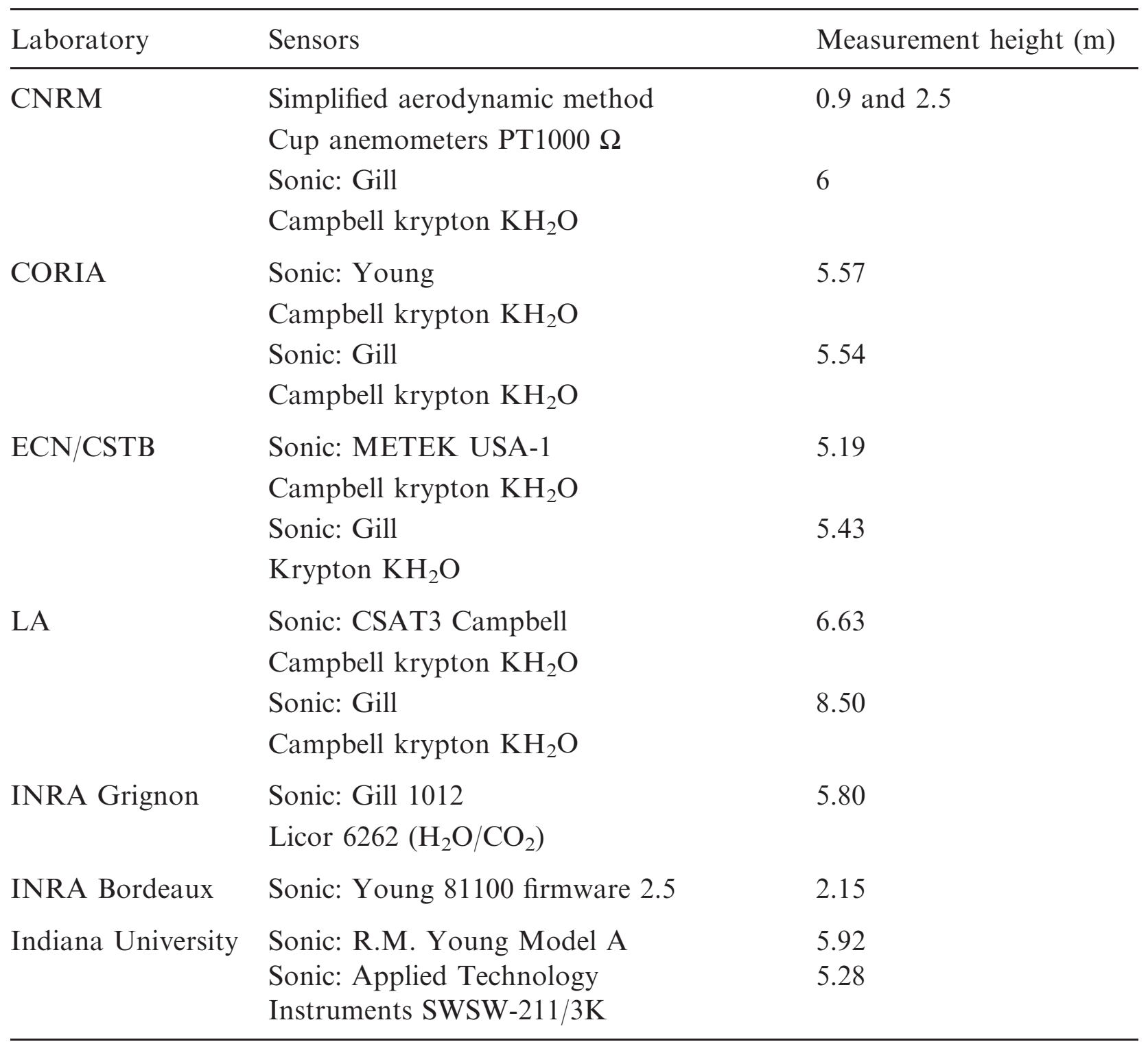

perature are less than $5 \%$, while wind direction measurements were within \pm $20^{\circ}$ from the mean direction.

Figure 4 shows a comparison between the time series of $\overline{w^{\prime} T^{\prime}}, \overline{w^{\prime} q^{\prime}}$ and $u_{*}$ obtained from each station. The number of estimates varied with time because some groups were unable to participate through the entire period, and the number of participating systems ranged from 2 to 9 for $\overline{w^{\prime} T^{\prime}}, 2$ to 6 for $\overline{w^{\prime} q^{\prime}}$, and 2 to 10 for $u_{*}$. The hourly means and standard deviations are also given. Between 0800 and $1600 \mathrm{UTC}$, the uncertainty for $\overline{w^{\prime} T^{\prime}}$ and $u_{*}$ is in the range of $10-20 \%$ (Figure $4 \mathrm{a}$ and c), whereas $\overline{w^{\prime} q^{\prime}}$ estimates are more scattered and their uncertainty lies between $20 \%$ and $40 \%$. Linear regressions between the results of each station and the average of all other stations were calculated for each station (Figure 5). For $\overline{w^{\prime} T^{\prime}}$ and $\overline{w^{\prime} q^{\prime}}$, only daytime $(0700-1800$ UTC) data are taken into account since the fluxes were very small at night. 

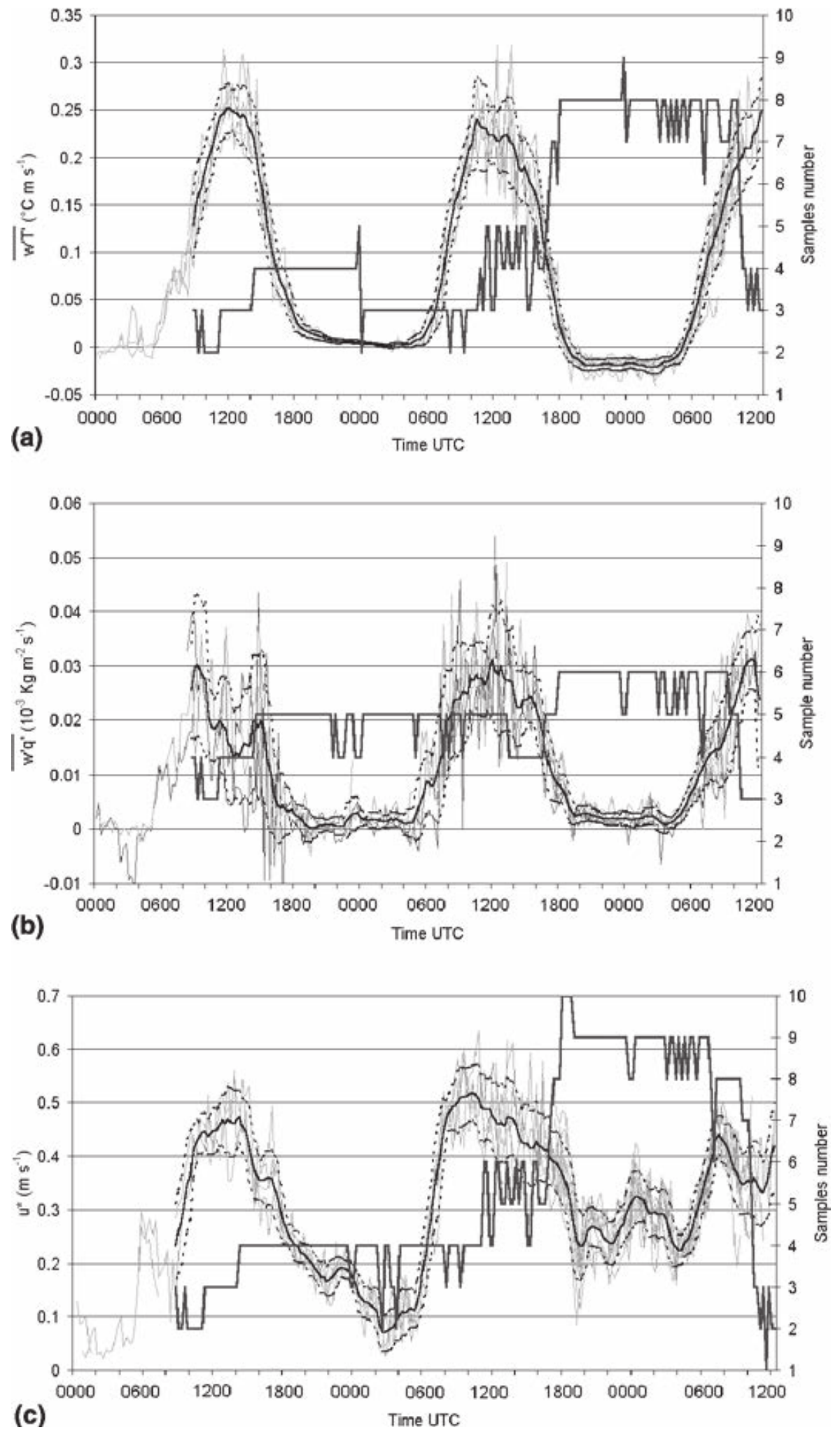

Figure 4. Time variation of the covariances of (a) $\overline{w^{\prime} T^{\prime}}$, (b) $\overline{w^{\prime} q^{\prime}}$, and (c) friction velocity $u_{*}$ during the intercomparison at the La Crau site (June 5-7). Thin grey line - the time series of one station; the solid and dotted black lines - the mean and standard deviation, respectively, of the available stations, averaged over one hour; the thick grey line - the number of stations (samples) available (right scale).

The comparison reveals relatively good overall agreement in $\overline{w^{\prime} T^{\prime}}$ estimates since half of the slopes have values ranging between 0.9 and 1.1 , but for some 

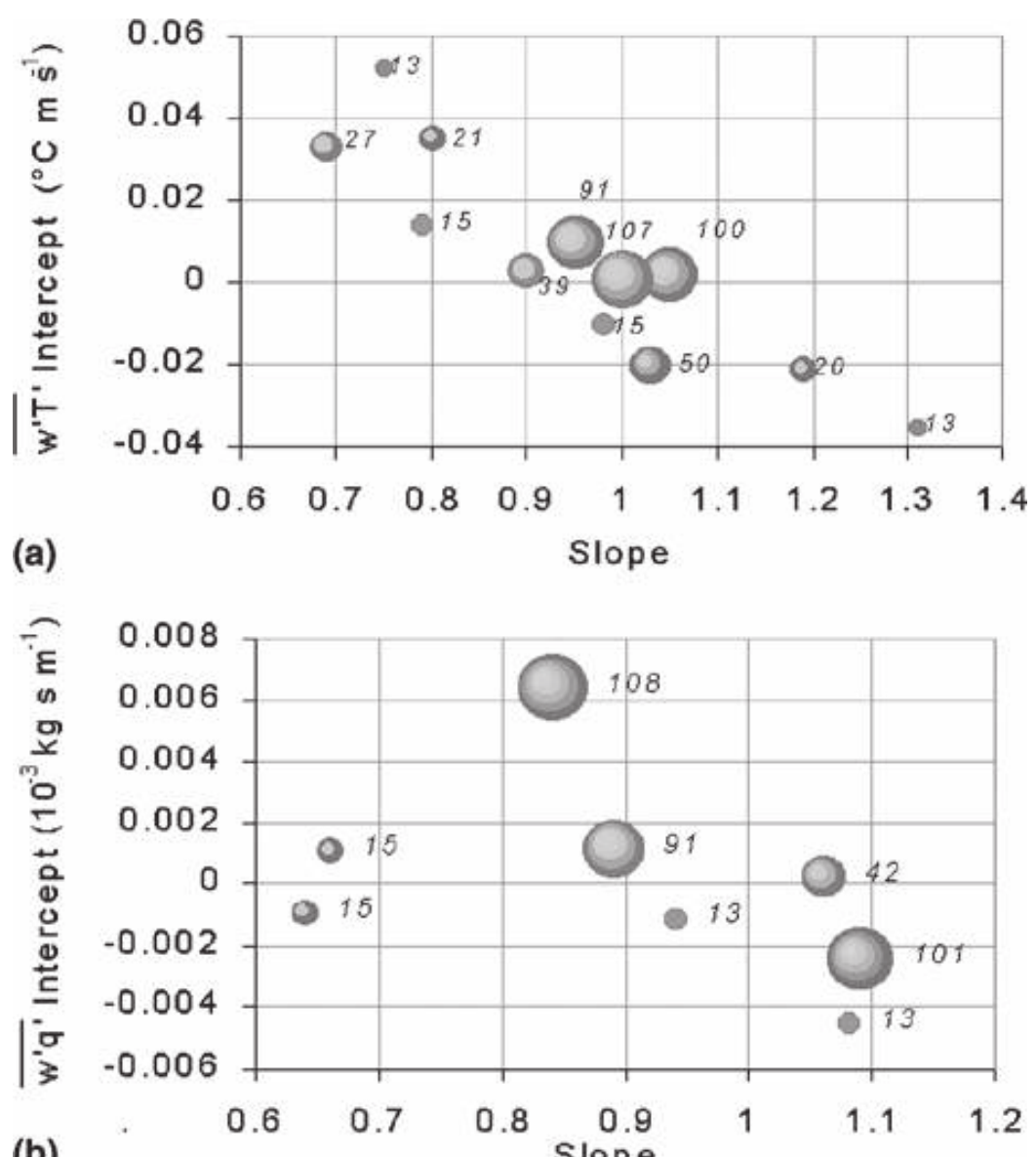

(b)

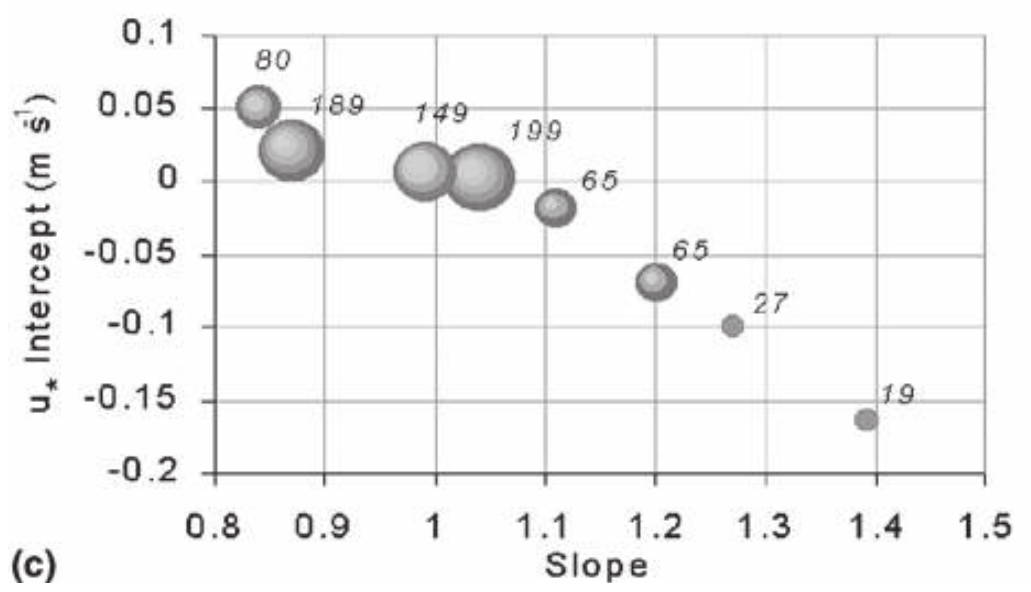

Figure 5. Intercepts and slopes of the linear regressions of individual station measurements versus averages of the available stations: (a) $\overline{w^{\prime} T^{\prime}}$ (b), $\overline{w^{\prime} q^{\prime}}$, and (c) $u_{*}$. The circle diameters and the associated numbers represent the number of measurements used in the regression.

stations the slope may vary up to 0.7 or 1.3 (Figure 5a) corresponding to a $30 \%$ difference in the flux. Similar results are obtained for the friction velocity (Figure 5c). The $\overline{w^{\prime} q^{\prime}}$ results (Figure 5b) show large discrepancies between the slopes and intercepts (evident in the observations of Figure 4b), the scatter being partly due to the sensitive calibration of Krypton hygrometers, which can vary over time.

In conclusion, the time series of the various covariance estimates agree quite well for $\overline{w^{\prime} T^{\prime}}$ and $u_{*}$, but are more scattered for $\overline{w^{\prime} q^{\prime}}$. The regression 
analysis indicates that about half of the stations show bias that is not negligible but could be corrected for, at least in part. Such corrections are not applied to the data presented here.

\subsection{INTERCOMPARISON OF SENSORS USED IN THE THERMODYNAMIC NETWORK}

Before the campaign, the 20 sensors of the T-RH network were compared in their shields, yielding a standard deviation of $0.08{ }^{\circ} \mathrm{C}$ for temperature, and $0.75 \%$ for relative humidity; the observed maximum average differences between two sensors were $0.40{ }^{\circ} \mathrm{C}$ and $3.2 \%$. The network operated continuously during the campaign with no missing data. It must be noted that data from instruments such as psychrometers could not be used, since a rapid degradation of sensor performance due to urban pollution was observed. Also, instruments such as the $\mathrm{KH}_{2} \mathrm{O}$ hygrometer required frequent cleaning during the 6-week period.

\subsection{Measurement issues at the urban stations}

The scientific study of urban atmospheres demands meteorological measurements that are representative of urban surface conditions at the local scale. Given the structure of the urban canopy and its considerable heterogeneity this is not an easy task (Oke, 1998). Conceptually, the 'surface' referred to here is that of the top of a volume extending from the measurement plane down to a depth in the ground at which vertical fluxes are zero over the period of observation (this concept is described in Oke, 1988). The volume itself therefore contains air, built features, trees and soil. This can be achieved by placing instruments in the inertial sub-layer, i.e., above the roughness sublayer, where their source areas (radiative and turbulent) are sufficiently large to 'see' a large enough portion of the surface and hence be representative of it (Schmid, 1997). To be in the inertial sub-layer instruments need to be mounted at 1.5 to about 3 times the average building height $H_{\mathrm{B}}$ although the spacing of the buildings also is important (Raupach et al., 1980). However, since the fetch requirement increases with height above the ground, the site must be sufficiently homogeneous and horizontally extensive to provide representative source areas, which usually means evaluating the detailed nature of the neighbourhood around the site out to a radius of $1-2 \mathrm{~km}$. Setting the instrumentation on top of a building is convenient for security, but to provide spatially representative data requires careful siting due to the influences of the building itself: wind flow distortion, upward radiation sensors view factor, footprint variation with height. Ground-based masts also encounter problems of representativeness, mainly due to the presence of 'obstacles' such as neighbouring buildings. 
The micrometeorological instrumentation operated at the five urban sites is specified in Table I. Component fluxes of the radiation balance, viz: downward and upward fluxes of shortwave radiation (visible and UV), $K \downarrow$ and $K \uparrow$, respectively, and longwave (infrared) radiation, $L \downarrow$ and $L \uparrow$, respectively were monitored. The turbulent fluxes of momentum, sensible heat $\left(Q_{\mathrm{H}}\right)$, and water vapour $\left(E\right.$, or latent heat $Q_{\mathrm{E}}=L_{V} E, L_{V}$ being the latent heat of vaporization) were obtained from eddy covariance measurements using a sampling rate of 10 or $20 \mathrm{~Hz}$. Hence the energy balance:

$$
K \downarrow-K \uparrow+L \downarrow-L \uparrow=Q^{*}=Q_{H}+Q_{E}+\Delta Q_{S}
$$

was evaluated where $Q^{*}$ is the net all-wave radiation, and $\Delta Q_{\mathrm{S}}$ includes heat storage in the ground, building materials, vegetation and canopy air volume.

The turbulent and radiation fluxes were all processed using 15- or 30-min block averages. Since the CAA, STJ and GLM stations were designed to provide reference data for the energy balance above typical urban and suburban districts, assessment of data representativeness required special attention in addition to the sensor intercalibration.

\subsubsection{City Centre Station (CAA)}

Eddy covariance instruments and radiometers were mounted on a Hilomast NX30 pneumatic tower. The base of the tower was $20.7 \mathrm{~m} \mathrm{agl}$ and the tower was operated at two heights depending upon the wind speed. When the tower was fully extended, in position ' Up', the top flux sensors (Level 1) were mounted at $43.9 \mathrm{~m}$ agl, while they were at $34.6 \mathrm{~m}$ agl in the lower position ('Down'). A lower set of sensors (Level 2) was mounted $6 \mathrm{~m}$ lower i.e. at 37.9 and $28.6 \mathrm{~m}$ in the 'Up' and 'Down' modes respectively (Grimmond et al., 2002). The average height of the surrounding buildings was $15.6 \mathrm{~m}$. The buildings in the area were quite homogeneous and of high density, resulting in good measurement representativeness of the city centre (Grimmond et al., 2002).

\subsubsection{North Suburban Station (STJ)}

The STJ experimental set-up potentially poses a problem related to the influence of the building itself on the measurements, since the wind impact on building faces generates wakes that alter the flow above the roof. The mast was located on the western part of the building roof, and wake effects were expected when the wind was from the east, essentially parallel to the long-axis of the building. The mean vertical velocity, analysed as a function of wind direction, showed that measurements made when the wind direction was in the sector $75-170^{\circ}$ were influenced by the wake. The influence of one tall building wake also appeared in the $310-350^{\circ}$ sector. These effects were observed only for wind velocities higher than $5 \mathrm{~m} \mathrm{~s}^{-1}$. Although these flow 
perturbations may be corrected, data from these wind directions are rejected (16\%) for the present study. Comparison of the momentum and heat fluxes obtained at the two levels suggests that the turbulence sensors were then within the constant flux layer (Figure 6).

\subsubsection{South Suburban Station (GLM)}

The area surrounding this site is quite heterogeneous resulting in a variety of flux footprints as a function of wind direction; this means that special care is needed when using these data for applications such as assessing
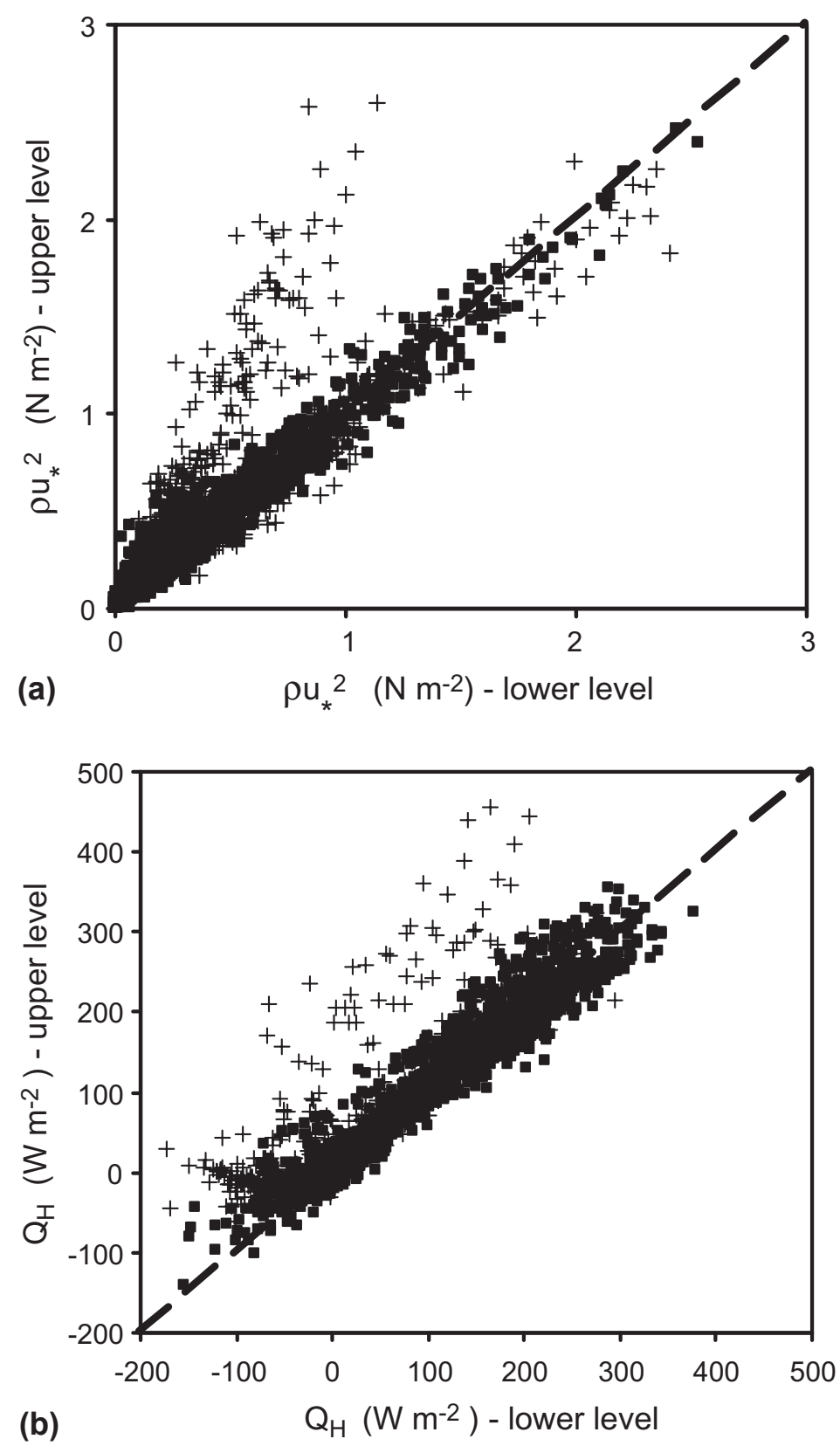

Figure 6. Comparison of the turbulent (a) momentum, and (b) sensible heat fluxes measured at two levels of the St Jerome suburban station (STJ). Squares are the data used in further analyses, and crosses are those discarded due to building wake effects. 
energy exchange models. The lower sensors, at $18 \mathrm{~m}$ agl, were approximately at the roof level of the closest buildings, implying that the sonic data were perturbed by building wakes when the wind was from the south and east. For westerly winds, especially during sea-breeze conditions, no systematic difference between the turbulent fluxes measured at the two levels was observed (Figure 7) although there is greater dispersion than at STJ (Figure 6). Data from the different wind directions should therefore be analysed differently.

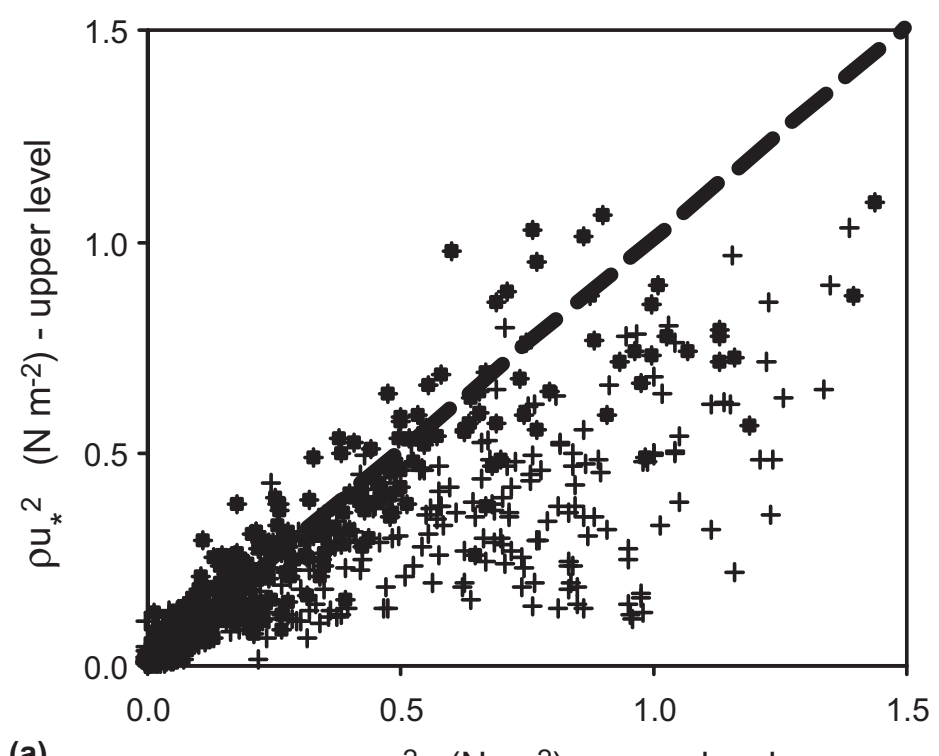

(a)

$\rho u_{*}^{2}\left(\mathrm{~N} \mathrm{~m}^{-2}\right)$ - upper level

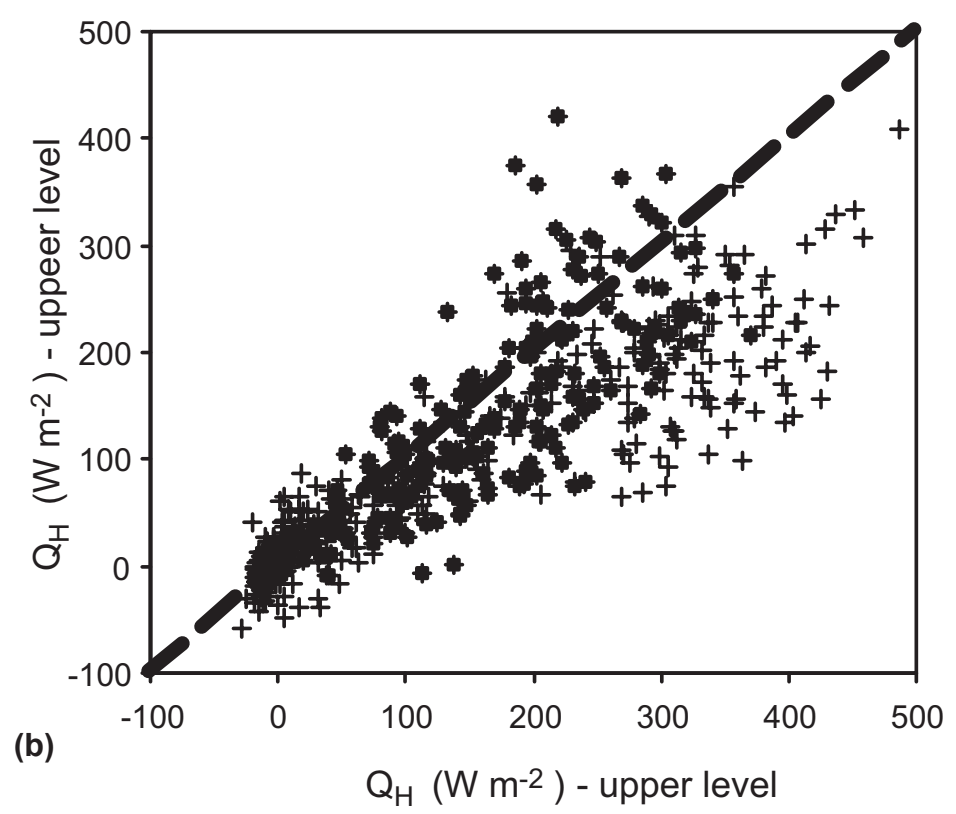

Figure 7. Comparison of the turbulent (a) momentum, and (b) sensible heat fluxes obtained during one week at two levels of the GLM suburban station. Superimposed squares indicate data with westerly winds. 

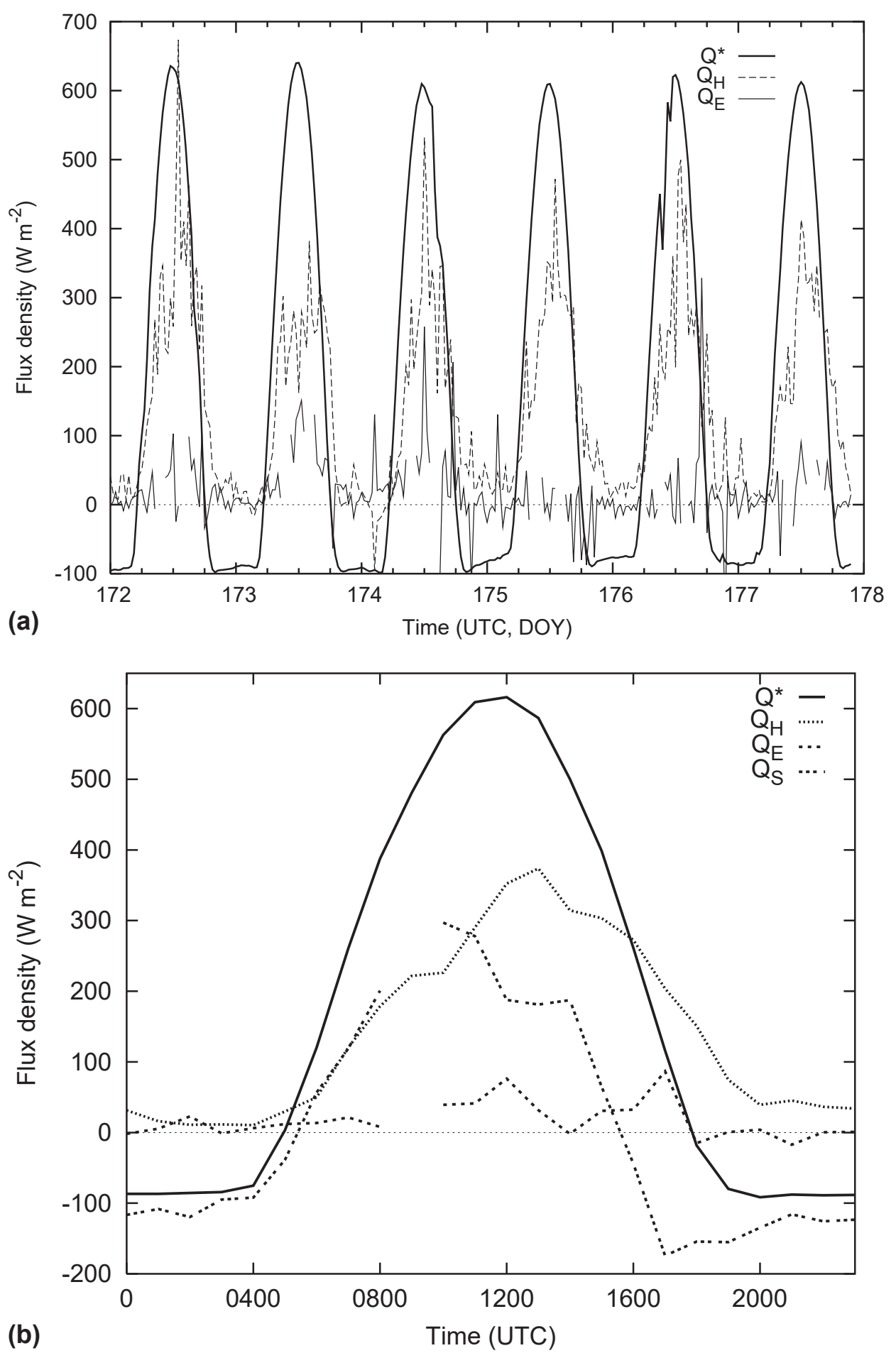

Figure 8. (a) Observed surface energy balance fluxes for the six days of IOP $2 \mathrm{a}$ and $2 \mathrm{~b}$ (days 172-178, June 21-26) at CAA and (b) ensemble mean for the period including the storage heat flux determined as the residual of the observed terms.

\section{Surface Energy Balance Fluxes in the City Centre}

\subsection{Surface energy balance}

Surface energy balance fluxes were measured for a total of 28 days (June 16July 14) at the CAA site. Hourly values are presented in Figure 8 for the 
6-day period of intensive observations IOPs $2 \mathrm{a}$ and $2 \mathrm{~b}$. The tower was fully extended throughout this period, with the top sensors at $43.9 \mathrm{~m}$ agl.

Results (Figure 8) show that the turbulent sensible heat flux is the dominant mode of heat transfer away from the surface during the middle of the day. As found at other densely developed urban sites in other cities the convective sensible heat flux remains positive throughout the night, sustained by large releases of heat stored in the urban fabric from the previous day (Oke, 1988; Grimmond and Oke, 1999, 2002). As expected, given the absence of vegetation cover at this site and the dry conditions during the measurement period, the latent heat fluxes are small. As found in other urban areas (Grimmond and Oke, 1999), $\Delta Q_{\mathrm{S}}$ peaks before solar noon and turns negative a couple of hours before the net all-wave radiation $\left(Q^{*}\right)$. Heat storage at this site has been investigated in detail by Roberts et al. (2003).

\subsection{Sensible heAt FluXes estimated USING SCINTILLOMETERS}

Line-averaged $Q_{\mathrm{H}}$ from the LASs was computed over 15-min periods using two methods (De Bruin et al., 1995; McAneney et al., 1995). The first method (M1 in Figure 9) combines the scintillometer-derived temperature scale $T_{*}$ with the friction velocity $u_{*}$, determined independently, to estimate $Q_{\mathrm{H}}=-\rho c_{\mathrm{p}} u_{*} T_{*}$, where $\rho$ is the air density and $c_{\mathrm{p}}$ the specific heat of air at

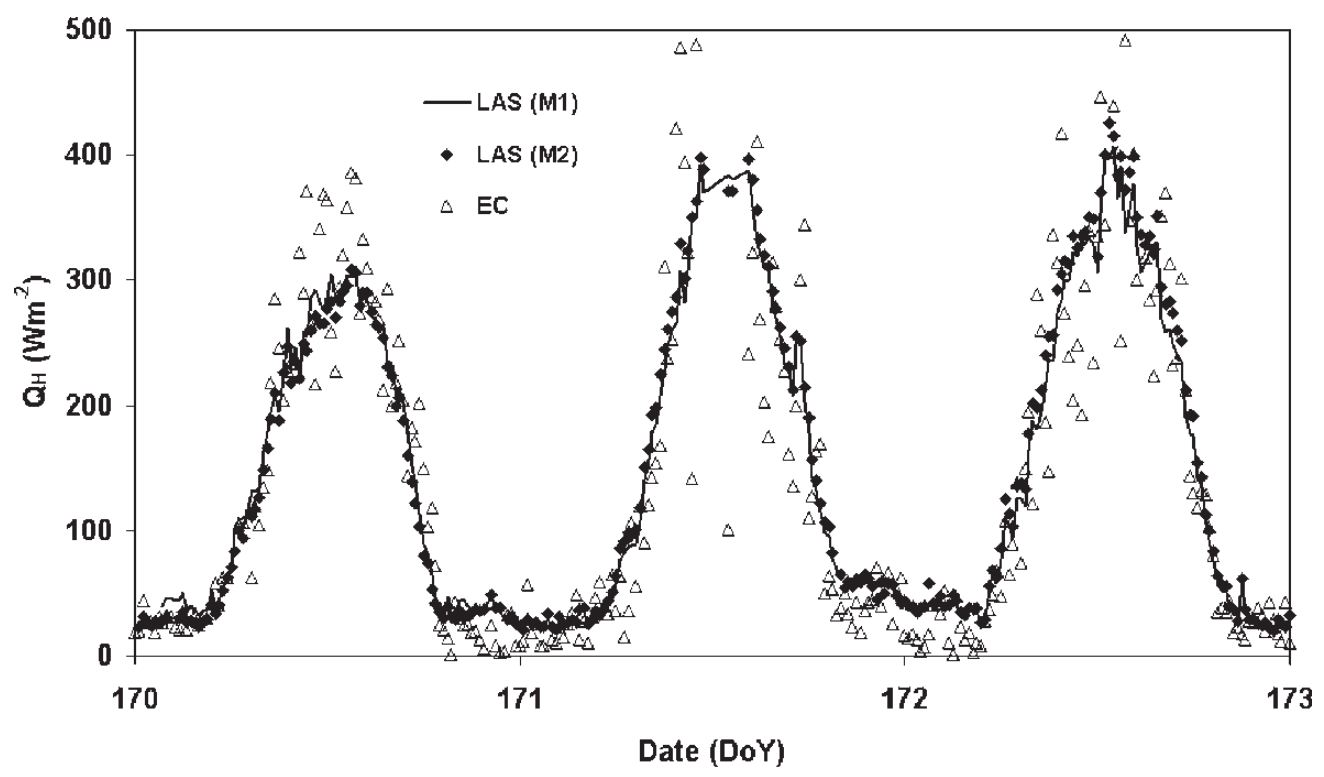

Figure 9. Comparison of the turbulent sensible heat flux derived from scintillometer measurements (LAS) using the mixed and free convection methods (M1 and M2, respectively) and the eddy covariance measurements (EC) from the city centre mast at CAA, for the period June 16-21. The short integration time (15 min) explains some of the variability observed in the EC values. 
constant pressure. The second method (M2) assumes free convection and $Q_{\mathrm{H}}$ is computed directly from the measured structure parameter for temperature, $C_{\mathrm{T}}^{2}$. The very good agreement found between both methods and the eddy covariance (EC) measurements on the CAA central mast (Figure 9) illustrates the promising potential of scintillometry for urban areas where spatial heterogeneity is large (Lagouarde et al., 2002a).

To evaluate the possible spatial variability of $Q_{\mathrm{H}}$, one scintillometer was moved between two transects during the experiment (double line, in Figure 1); the observed differences from the scintillometers reached $15 \%$. The location of the flux footprint of each scintillometer has not been calculated, yet this could help determine whether these differences are due to variations in the surface area upwind of the optical paths, and how these differences vary according to the wind direction. Spectral analysis of the optical scintillations has also been undertaken to evaluate the refraction and absorption components in the signal, so as to ensure the final quality of the data (Irvine et al., 2002).

\subsection{Preliminary evaluation of TEB using measured surface energy FLUXES}

The Town Energy Balance (TEB) scheme of Masson (2000) parameterises energy exchanges between the urban surface and the atmospheric boundary layer. TEB has been evaluated off-line using observations of local scale fluxes and surface temperatures from Mexico City and Vancouver (Masson et al., 2002), and with the Meso-NH atmospheric model for Paris (Lemonsu and Masson, 2002). In this study, the TEB scheme is used for built areas and the ISBA (Interaction Soil-Biosphere-Atmosphere) scheme (Noilhan and Planton, 1989) for vegetated areas. The two models are combined using the plan areas of built and vegetated surfaces as the weighting. The performance of the combined model is evaluated for the city centre of Marseille using the observed temperatures and surface fluxes.

Here a static modelling domain was defined for the area within a $500-\mathrm{m}$ radius centred on the CAA site. The TEB input parameters (surface cover fractions and geometric dimensions of the streets) were derived from the analysis of aerial photographs (Grimmond et al., 2002) and the database of building heights (Section 2). Thermal properties of materials were assigned based on published sources (ASHRAE, 1981; EDF and Atelier du Patrimoine de la ville de Marseille, 1983; Oke, 1987). Given the importance of traffic in the city centre, an anthropogenic heat flux was estimated following the method of Grimmond (1992). In off-line mode the TEB-ISBA models are forced by observations of air temperature, humidity, wind speed, 

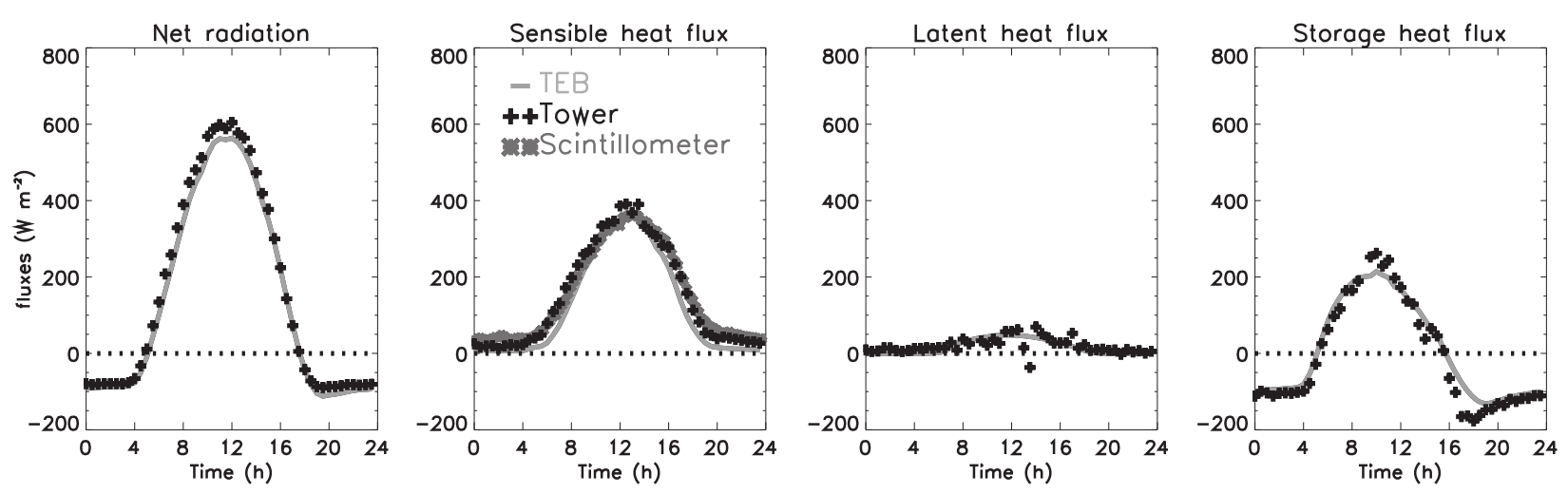

Figure 10. Comparison between observed and simulated surface energy balance fluxes in the city centre, averaged over 21 days. Black crosses - observed eddy covariance fluxes; continuous line - simulated fluxes using TEB, which are an average of the fluxes from roads, walls, roofs and natural surface cover. Grey stars in the turbulent sensible heat flux graph are calculated from the scintillometer data using the free-convection method (from Lemonsu et al., 2004).

and incoming solar and longwave radiation at the top of the tower. For Marseille, TEB-ISBA is being evaluated using measurements of air temperature from within the street canyons, the surface temperatures of roads, roofs and walls (Section 8), and fluxes from the CAA tower and the LAS scintillometers (Lemonsu et al., 2004). It is assumed that the amount of energy leaving the top of the canopy does not change with height, as in a classical 'constant flux' atmospheric surface layer, which can be true only for a horizontal spatial average, since vertical and horizontal flux divergence prevails in the roughness sublayer. Only heat flux comparisons are shown here and they are simulated well (Figure 10). The model succeeds in producing a positive turbulent sensible heat flux at night, and the correct daily cycle of heat storage (Table IV). High resolution, 3-D simulations are planned, using the non-hydrostatic, mesoscale atmospheric model Meso-NH (Lafore et al., 1998) with TEB-ISBA parameters as defined here for the city centre.

\section{TABLE IV}

Comparison between observed (CAA) and simulated (TEB) surface energy fluxes over the city centre (RMSE = root-mean-squared error).

\begin{tabular}{lcl}
\hline Flux & $\begin{array}{l}\text { Bias (simulated-observed) } \\
\left(\mathrm{W} \mathrm{m}^{-2}\right)\end{array}$ & $\begin{array}{l}\mathrm{RMSE} \\
\left(\mathrm{W} \mathrm{m}^{-2}\right)\end{array}$ \\
\hline$Q^{*}$ & -7.2 & 28.8 \\
$Q_{\mathrm{H}}$ & -14.5 & 61.2 \\
$Q_{\mathrm{E}}$ & -7.4 & 42.3 \\
$\Delta Q_{\mathrm{S}}$ & +13.5 & 66.2 \\
\hline
\end{tabular}




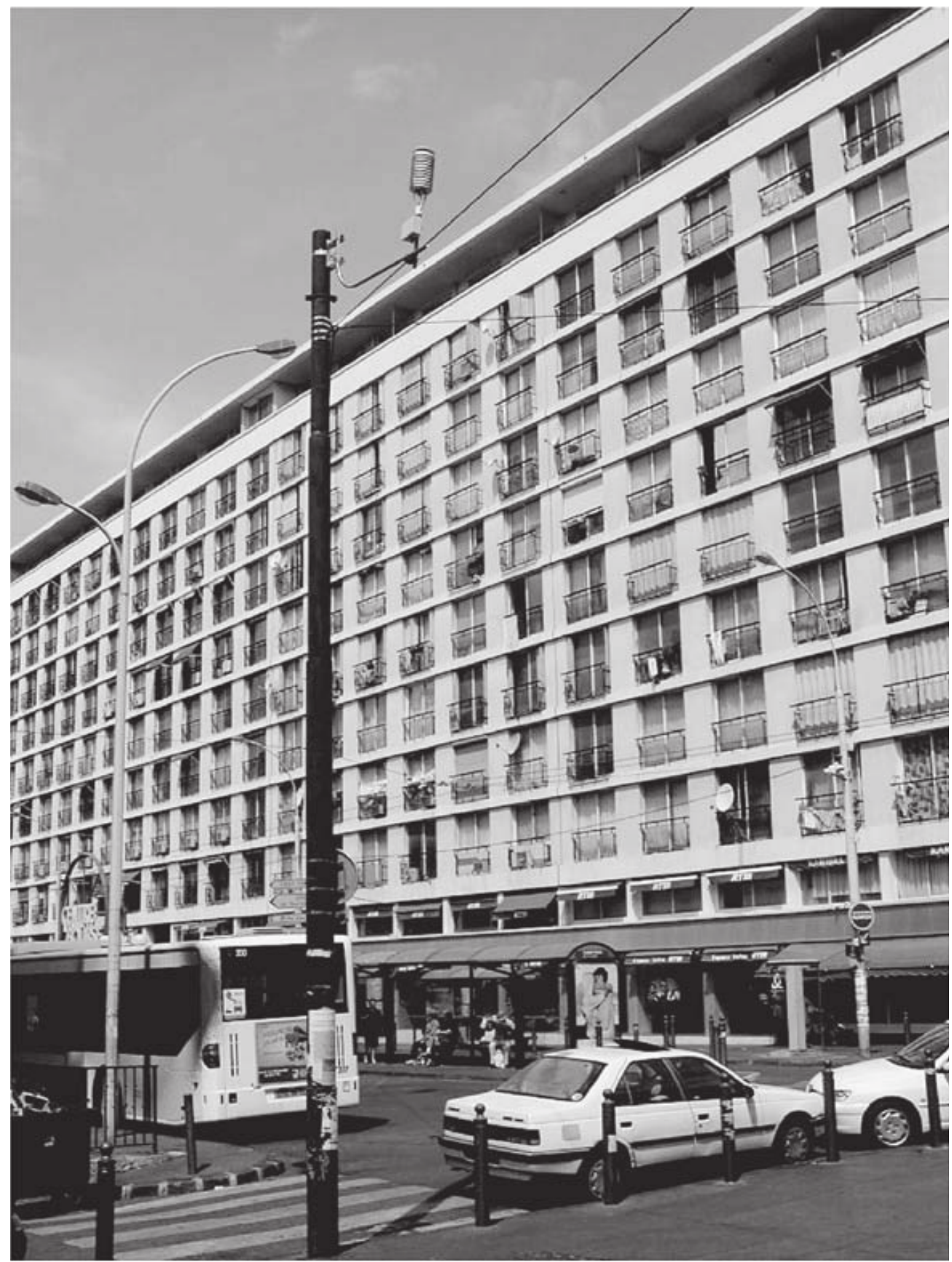

Figure 11. Example of a shielded T-RH sensor assembly at a site in the city centre.

\section{Temperature and Moisture Variability in the Urban Canopy}

\subsection{INSTRUMENTAL SET-UP}

The T-RH network sites were chosen after considering the patterns produced by high-resolution, numerical simulations with the Meso-NH model including the TEB urban scheme. The nested-grid runs, with horizontal resolutions from $4 \mathrm{~km}$ to $250 \mathrm{~m}$, simulated the so-called ESCOMPTE IOP 0; situations observed during the preliminary campaign from June 29 to July 1, 2000. The thermodynamic fields over the Marseille area were simulated for a northwesterly flow (June 29), a westerly breeze (June 30), and a southerly breeze 
(July 1), corresponding to flows expected during the full 2001 campaign. Analysis of these preliminary simulations, using empirical orthogonal functions, was used to define the most appropriate measurement locations so as to detect the main features of the urban heat island and humidity distribution (Pigeon et al., 2002). In addition, the sensor locations were chosen to document the thermodynamic response of a variety of urban landscape types (dense centre, suburban, city outskirts), and to include a range of distances from the shoreline according to the observed mean flows (Figure 1). A measurement height of $8 \mathrm{~m}$ was chosen and the sensors were exposed in the middle of the street (Figure 11). This position minimized potentially confusing microscale influences from the ground and building walls, especially in the dense city centre.

\subsection{THERMODYNAMIC MEASUREMENTS IN THE URBAN CANOPY}

Here analysis is restricted to three stations aligned along a south-west to north-east axis at distances ranging from $2.5 \mathrm{~km}$ (dense urban, city centre area) to $12.5 \mathrm{~km}$ (near-rural area) from the coast The mean daily variation of potential air temperature and specific humidity at these stations was computed for two characteristic meteorological situations: days with north-westerly continental mistral wind (4 days, Figure 12), and those with a weak
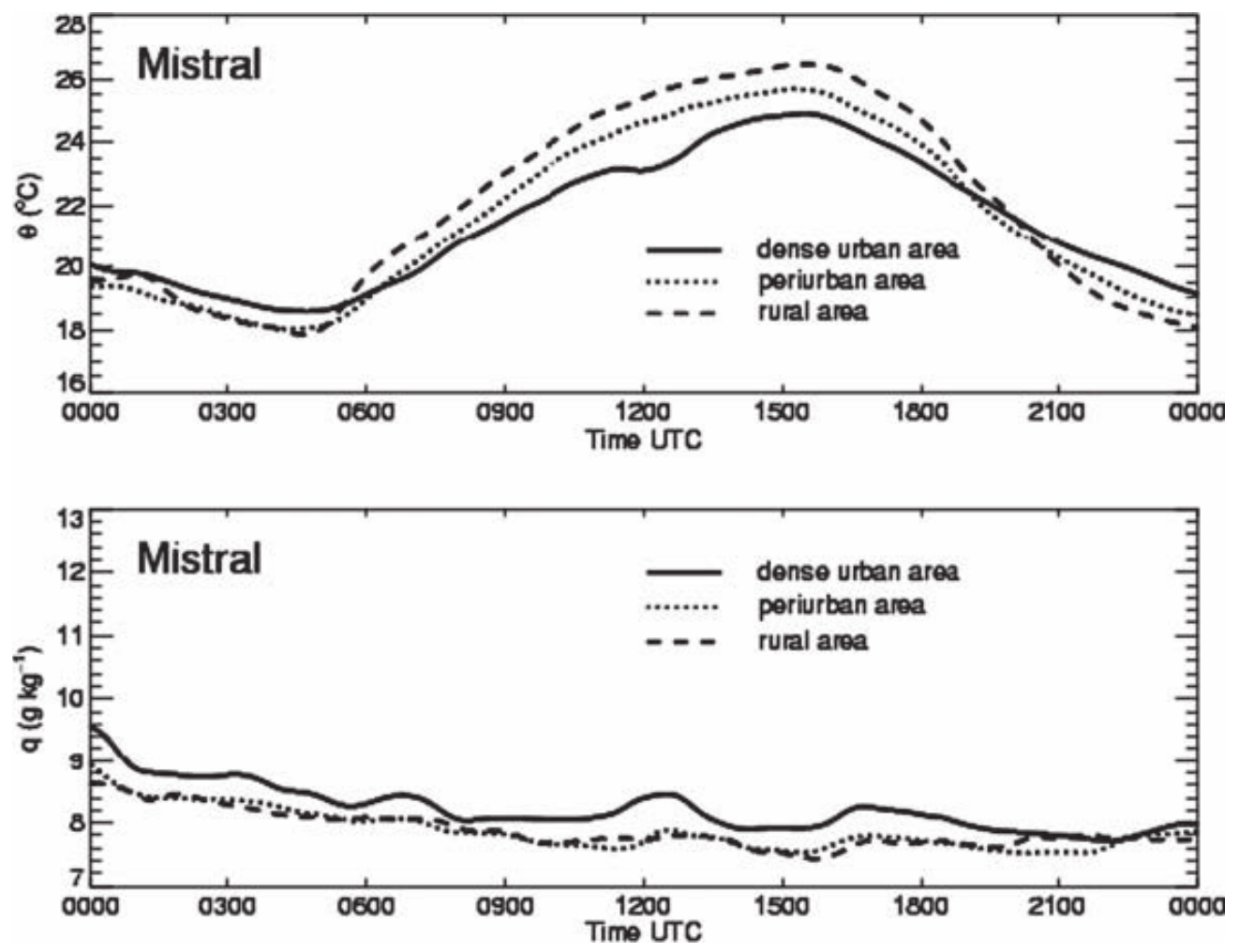

Figure 12. Diurnal cycles of average potential air temperature and specific humidity during mistral (north-westerly wind) conditions, at dense urban, suburban and rural sites. 
synoptic flow and a westerly sea breeze (24 days, Figure 13). Interpretations are complicated by the competing and augmenting effects of distance from the coast, intensity of urban development and elevation.

In mistral conditions the specific humidity is relatively uniform across the whole urban area, but there is a decrease through the daytime as the air mass dries in these windy conditions. The air temperature observations show a weak heat island effect, with a temperature difference of about $+1{ }^{\circ} \mathrm{C}$ between the rural and downtown sites during the first half of the night, while the rural and suburban station differences are small. During the daytime, only small temperature differences between the stations are observed.

Thermodynamic differences between stations are more prominent in the case of sea-breeze days (Figure 13); there is always a moisture gradient: moisture decreases with increasing distance from the sea. The nocturnal urban heat island magnitude reaches about $2.5^{\circ} \mathrm{C}$ only, though the urban heat island, whilst favoured by low winds, may be reduced by the vicinity of the sea. The height of measurement may also play a role in the observed temperature differences since microclimatic effects decrease with height above the surface. The pattern of warming in the morning is very different at the three sites: from 0500 to 0700 UTC, the temperature increases from 17 to $23{ }^{\circ} \mathrm{C}$ at the rural stations, while it increases only from 19 to $22{ }^{\circ} \mathrm{C}$ in the city centre. After this warming period, the inland rural station is warmer than the others by about $1-2{ }^{\circ} \mathrm{C}$, due to the impact of the sea breeze, while the dense city centre is slightly cooler than the suburban areas by about $1^{\circ} \mathrm{C}$. Another
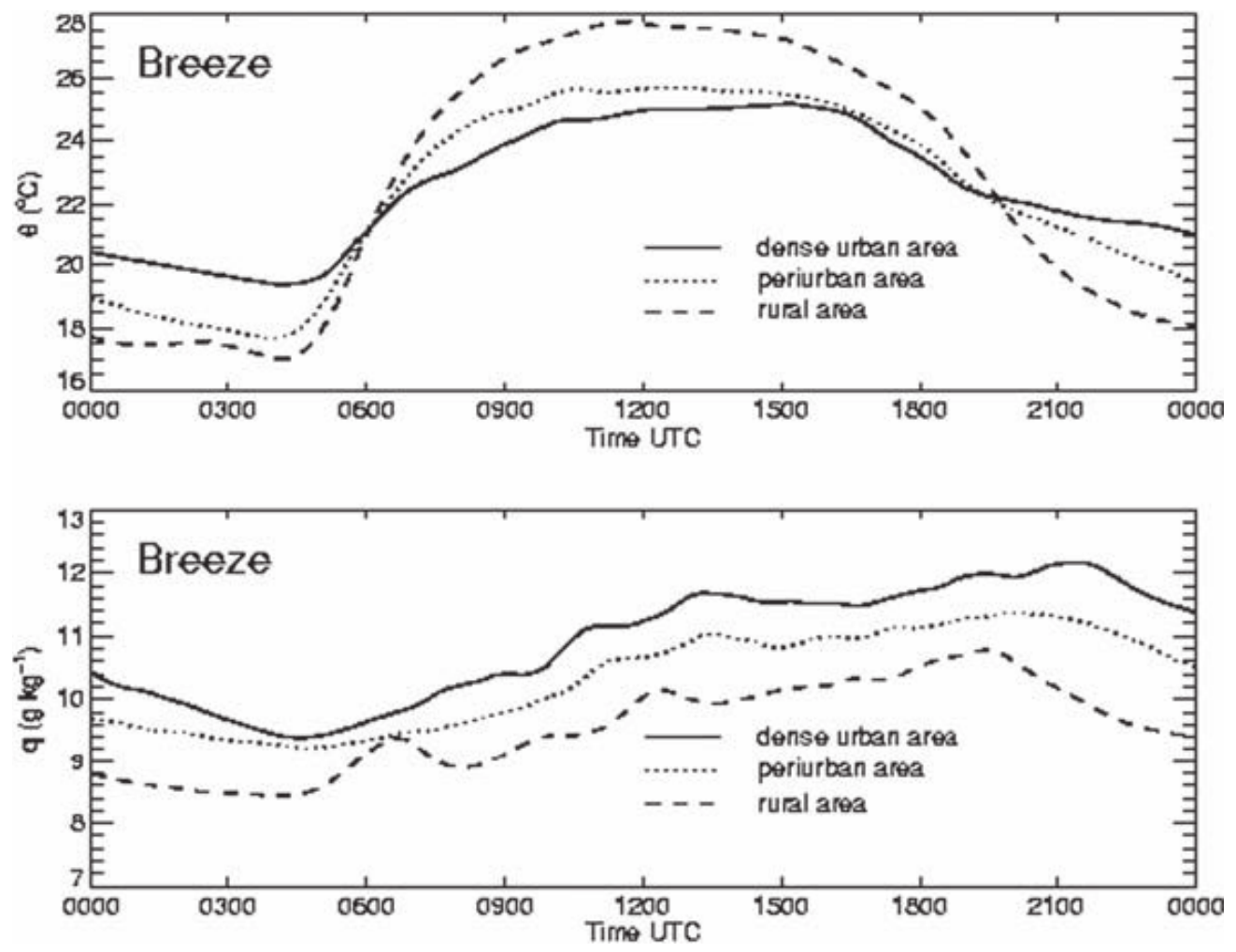

Figure 13. Same as Figure 12, but for land/sea-breeze conditions with weak synoptic wind. 
striking difference between Figures 12 and 13 is the steady temperature increase from 0500 to 1500 UTC during mistral days, whereas on sea-breeze days temperature varies by less than $1{ }^{\circ} \mathrm{C}$ between 1000 and 1600 UTC. These general features demonstrate the influence of mesoscale flows, that is sea breezes or the mistral, on the temperature and humidity fields in the area of Marseille; their patterns are a mix of the three influences: coast, city, and relief.

\section{Urban Boundary Layer 3-D Structure}

The 3-D structure of the urban boundary layer was documented with the help of airborne measurements, radiosondes, and remote sensing with lidars, sodars and UHF radar. This 3-D exploration was mainly designed to study, (i) the mesoscale flow circulation linked to the sea breeze, the mistral, and slope winds, and (ii) the vertical structure of the ABL to assess the urban influence on the lower troposphere.

\subsection{REMOTE SENSING FROM THE GROUND}

\subsubsection{UHF Radar}

A five-beam UHF wind profiler was operated continuously at the OBS station for the whole campaign. Profiles of horizontal wind, vertical velocity, reflectivity $\left(C_{n}^{2}\right)$, and Doppler spectral width were obtained in clear air every $5 \mathrm{~min}$ from $100 \mathrm{~m}$ agl up to about $2 \mathrm{~km}$ (depending on atmospheric conditions), with a $75-\mathrm{m}$ vertical resolution. The instrument and processing techniques are described by Jacoby-Koaly et al. (2002).

Figure 14 presents time-height sections of UHF observations in the lowest $1000 \mathrm{~m}$ during the June 25 sea-breeze episode. The continuous black/white line shows the top of the ABL deduced from the maximum reflectivity level in Figure $14 \mathrm{~b}$. The 1-h averaged dissipation rate of turbulent kinetic energy $\varepsilon$ (Figure 14c) is deduced from the Doppler spectral width. The morning ascent of the ABL top culminates at $750 \mathrm{~m}$ agl at around $1400 \mathrm{UTC}$; after 1500 UTC the ABL starts to collapse when the wind strengthens from the south (Figure 14a), indicating sea-breeze reinforcement. A large fraction of the heat flux is used to warm the relatively cool and humid marine air advected inland, at the expense of ABL vertical development. The weakness of the buoyancy flux explains the shallowness of the ABL in the morning and its collapse early in the afternoon. As shown in Figure 14c, the turbulence, concentrated within the $\mathrm{ABL}$, is rather weak with $\varepsilon$ values lower than $10^{-3} \mathrm{~m}^{2} \mathrm{~s}^{-3}$. 

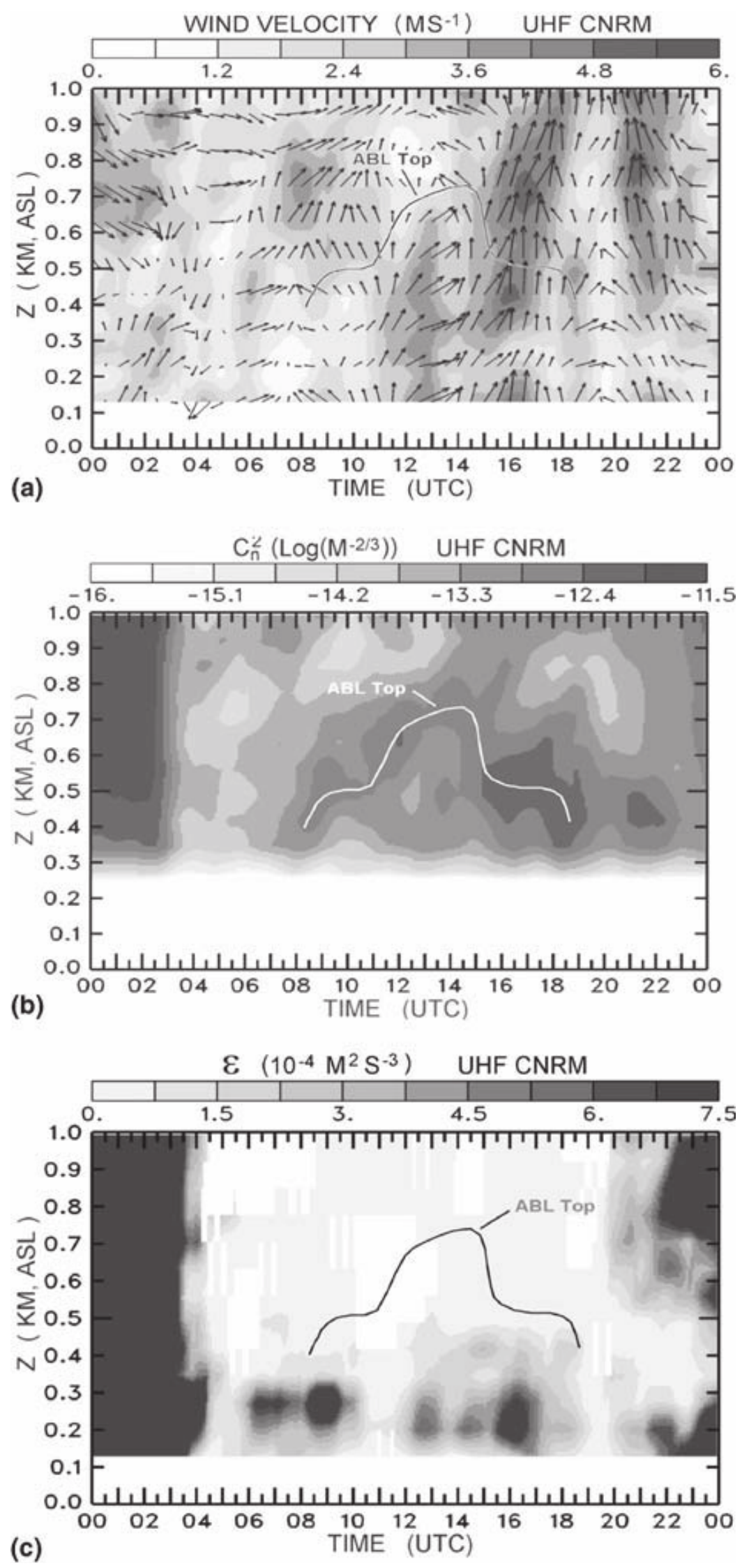

Figure 14. Time-height sections of UHF profiler observations at the Observatoire (OBS) on June 25. (a) Horizontal wind velocity (b), $C_{n}^{2}$ reflectivity, and (c) dissipation rate of turbulent kinetic energy $\varepsilon$. The superimposed black or white line is the top of the ABL as deduced from the maximum UHF reflectivity. 
TABLE V

Sodars and their characteristics.

\begin{tabular}{|c|c|c|c|}
\hline Instrument type & Sodar Remtech PA1 & $\begin{array}{l}\text { Mini-sodar } \\
\text { aerovironment }\end{array}$ & $\begin{array}{l}\text { Sodar RASS Metek } \\
\text { DSDPA 90-24 }\end{array}$ \\
\hline Operator & ECN/CSTB & CORIA & Alliance Technologies \\
\hline Location & STJ & GLM & VAL \\
\hline Parameters measured & $U, V, W, C_{\mathrm{T}}^{2}, \sigma_{\mathrm{w}}$ & $U, V, C_{\mathrm{T}}^{2}, \sigma_{\mathrm{w}}$ & $U, V, C_{\mathrm{T}}^{2}, \sigma_{\mathrm{w}}, T_{\mathrm{v}}$ \\
\hline $\begin{array}{l}\text { Meas. range } \\
(\min -\max )\end{array}$ & $70-350 \mathrm{~m} \mathrm{agl}$ & $10-150 \mathrm{~m}$ arl & $50-500 \mathrm{~m} \mathrm{agl}$ \\
\hline Vertical resolution (m) & 20 & 5 & 25 \\
\hline Time resolution (min) & 15 & 15 & 15 \\
\hline Period of operation & June 20-July 13 & June 15-July 13 & June 13-July 16 \\
\hline Measurement time & $\begin{array}{l}\text { Daytime }(0700- \\
1700 \text { UTC). }\end{array}$ & $\begin{array}{l}\text { Daytime (0600- } \\
-2100 \text { UTC) }\end{array}$ & Continuous \\
\hline Operation mode & $\begin{array}{l}\text { No operation } \\
\text { on week-ends and } \\
\text { at night }\end{array}$ & $\begin{array}{l}\text { Low power on } \\
\text { week-ends and } \\
\text { nights }\end{array}$ & $\begin{array}{l}\text { Some interruptions } \\
\text { from July } 10-16\end{array}$ \\
\hline
\end{tabular}

$C_{\mathrm{T}}^{2}=$ structure coefficient (reflectivity); $\sigma_{\mathrm{w}}=\mathrm{rms}$ vertical wind velocity; $T_{\mathrm{v}}=$ virtual temperature; agl = above ground level; arl = above roof level; CSTB = Centre Scientifique et Technique du Bâtiment, Nantes, France.

\subsubsection{Sodars}

Three sites were equipped with sodars and mini-sodars, two within the city (GLM and STJ) and the third one at VAL (Table V), the last being equipped with a Radio Acoustic Sounding System (RASS) that provides profiles of 'sonic' temperature (see Section 4.1).

Figure 15 displays time--height sections of 'sonic' temperature, wind speed, and Doppler spectral width obtained from the RASS sodar at VAL on June 25; the ABL-top curve obtained from the UHF profiler is added. There is fairly good agreement between wind fields measured by the sodar (Figure 15a) and the radar (Figure 14a). The sodar Doppler spectral width (Figure 15c), which is related in part to turbulence, shows a similar diurnal pattern to that of $\varepsilon$ derived from the UHF profiler (Figure 14c). In particular, the region of the widest Doppler spectrum and of large $\varepsilon$ values is confined within the ABL and below $500 \mathrm{~m}$. Finally, it also appears that the RASS observations provide a good representation of the diurnal temperature cycle (Figure 15b).

Figure 16 shows variations of wind speed and direction observed up to $150 \mathrm{~m}$ during the afternoon of June 25, using the mini-sodar at the GLM suburban station. On each profile, the wind direction and speed were relatively constant up to $100 \mathrm{~m}$ (Figure 16a), however, the wind direction rotated during the afternoon from west to south. The fine vertical resolution of the 

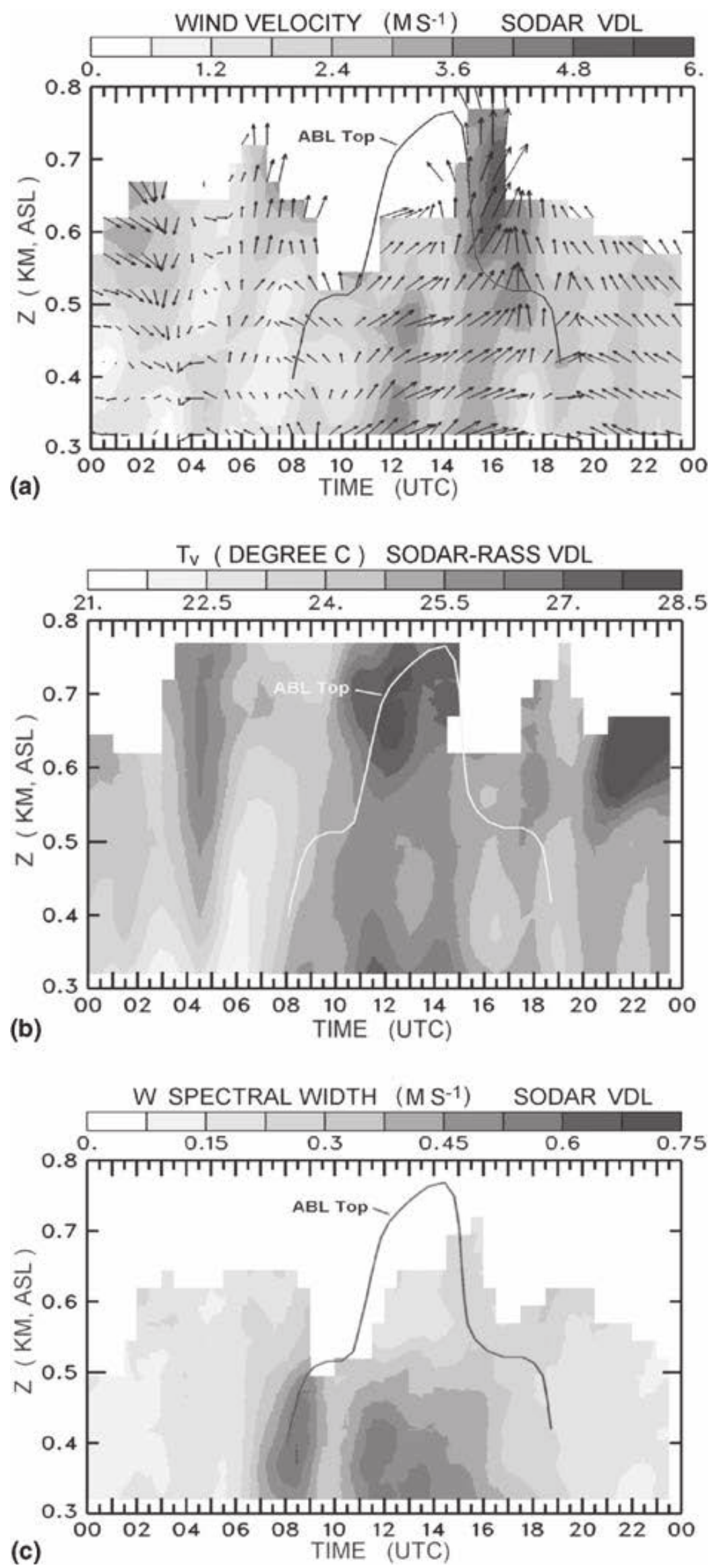

Figure 15. Time-height sections of sodar-RASS observations at Vallon Dol (VAL) on June 25. (a) Horizontal wind velocity, (b) virtual temperature, and (c) sodar Doppler spectral width. The superimposed black or white line is the top of the ABL as deduced from the maximum UHF reflectivity (see Figure 14). 

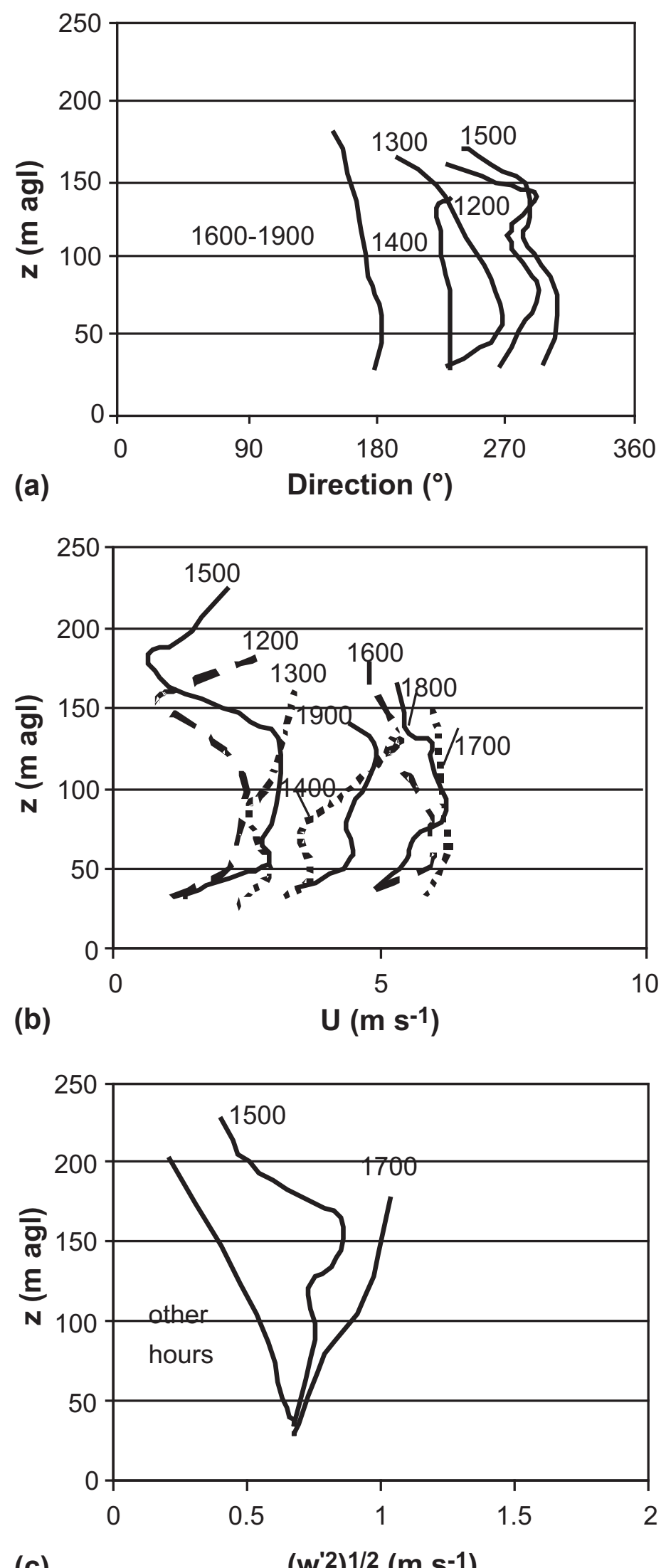

(c)

Figure 16. Vertical profiles of mini-sodar observations at the GLM suburban station. (a) Wind direction, (b) wind speed, and (c) vertical wind speed rms.

mini-sodar $(5 \mathrm{~m})$ clearly shows this rotation at levels above $100 \mathrm{~m}$. During the afternoon, the mean wind speed also increased (Figure 16b). These fea- 
tures reveal a well-established sea breeze from the west during the day and a weaker one growing from the south later in the afternoon. The vertical velocity variance profiles (Figure 16c) show irregular behaviour above $50 \mathrm{~m}$ that requires further analysis.

\subsubsection{Lidars}

Two lidars were operated jointly in scanning modes at the south-west edge of the VAL site, a location that overlooks most of the city from $285 \mathrm{~m}$ asl. The UV angular lidar measured angular profiles of ozone concentration with dual 286.3-282.4 $\mathrm{nm}$ wavelengths, and the total extinction coefficient with the $286.3 \mathrm{~nm}$ wavelength. Angular scans were obtained over a 30 -min period per scan, giving $100-\mathrm{m}$ spatial resolution, and $250-2500 \mathrm{~m}$ range in each measurement direction. The atmospheric total extinction includes Rayleigh scattering, large size aerosol interactions (e.g., Mie) and molecular absorption. However, the extinction is only slightly affected by ozone concentration and the correction for ozone absorption did not show major changes in the results; the observed stratification may be correlated to aerosol concentration. The extinction coefficient $\alpha$ at the radial distance $r$ is extracted from the backscattered signal power $\mathrm{P}$ using the slope method:

$$
\alpha(r)=-1 / 2 d n\left[r^{2} P(r)\right] / d r .
$$

Although this technique assumes slow spatial variation of the backscatter coefficient, it is sufficient, as a first step, to examine the atmospheric stratification.

Figure 17 is a vertical cross-section of the extinction along the $185^{\circ}$ azimuth and illustrates the atmospheric stratification during the sea breeze of

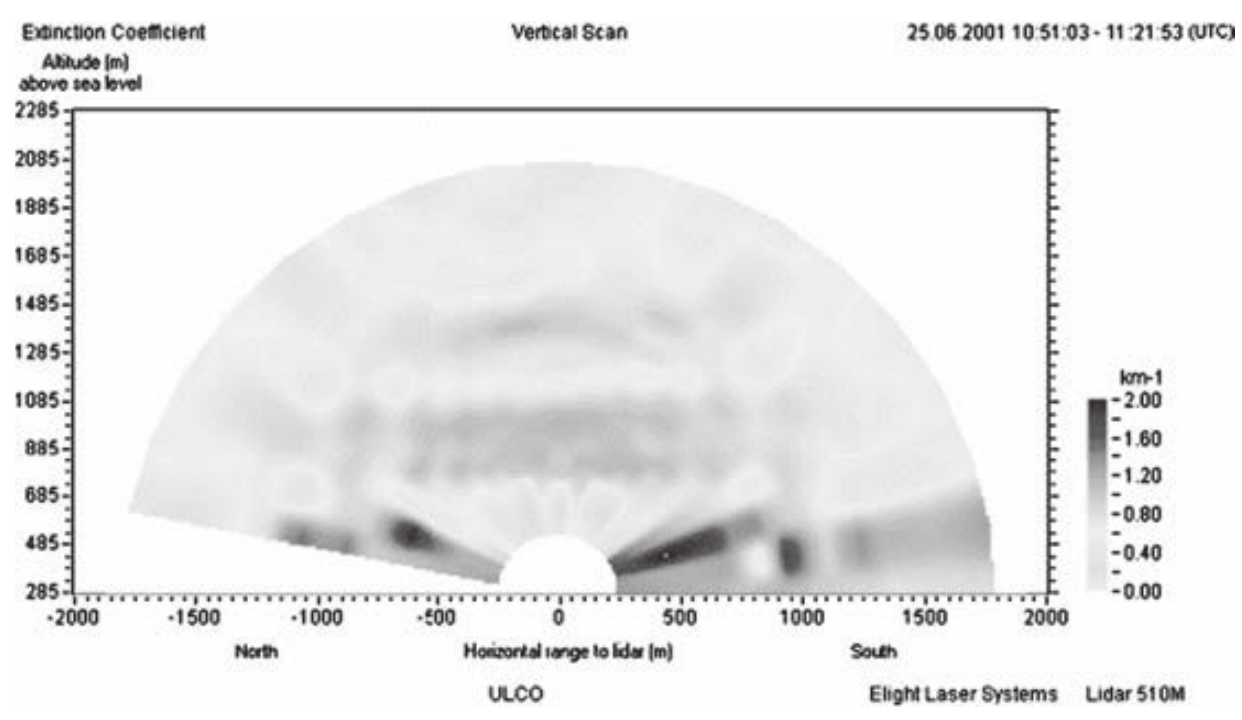

Figure 17. Vertical cross-section of the optical extinction retrieved by the Elight angular lidar at Vallon Dol, June 25 at about 1100 UTC. 
June 25 (1100 UTC). The lower layer below $685 \mathrm{~m}$ asl is in the sea-breeze flow. While the ABL top has been observed at about $700 \mathrm{~m}$ asl above Marseille (Section 7.1.1), the observed layer between 685 and $1100 \mathrm{~m}$ shows the ABL top at approximately $1100 \mathrm{~m}$ asl at the VAL site, which is located at an altitude of $285 \mathrm{~m}$ asl. At higher altitude, above $1100 \mathrm{~m}$, the observed plumes are under investigation by intercomparing the set of lidar measurements covering the whole ESCOMPTE region.

The flow circulation around VAL was documented by the transportable wind lidar (TWL) within a semi-sphere of radius ranging from 6 to $15 \mathrm{~km}$, depending on the aerosol content in the ABL and the refractive index of turbulence (Drobinski et al., 1999). The TWL operated in the infrared at $10.6 \mu \mathrm{m}$ and was sensitive to $1-\mu \mathrm{m}$ size particles that are excellent tracers of flows in the troposphere. The TWL provided radial velocity measurements along the line-of-sight, and the pulse repetition frequency was $2 \mathrm{~Hz}$. The accuracy was about $0.3 \mathrm{~m} \mathrm{~s}^{-1}$ for 10 accumulated shots (Dabas et al., 1999) and the radial range resolution was about $200 \mathrm{~m}$. The TWL previously proved its ability to document phenomena such as thermal winds and orographic flows (Drobinski et al., 2001, 2003), as well as the structure of turbulence in an urban zone (Drobinski et al., 1998).

Vertical cross-sections with elevations from $-90^{\circ}$ to $90^{\circ}$ from zenith were swept with an increment of $3^{\circ}$, at azimuth angles equally spaced by $30^{\circ}$. An example of a radial velocity vertical cross-section is shown in Figure 18, for elevations between $0^{\circ}$ and $90^{\circ}$ and an azimuth of $110^{\circ}$ (i.e., towards east and south-east) at about 1000 UTC on June 25. Negative (positive) radial velocities correspond to air flowing towards (away from) the TWL. Here, the sea breeze moves inland (i.e., away from the TWL) in a 1-km deep layer, approximately $90^{\circ}$ from the coastline (see arrows in Figure 18), with a return flow aloft between 1 and $1.5 \mathrm{~km}$ asl. In the eastern suburbs of Marseille, a reverse flow in the opposite direction is observed. That flow may originate from an urban breeze induced by the thermal gradient between Marseille $\left(26^{\circ} \mathrm{C}\right)$ and Gemenos $\left(16^{\circ} \mathrm{C}\right)$, the rural area about $20 \mathrm{~km}$ east of Marseille, similar to the observations of Ohashi and Kida (2002).

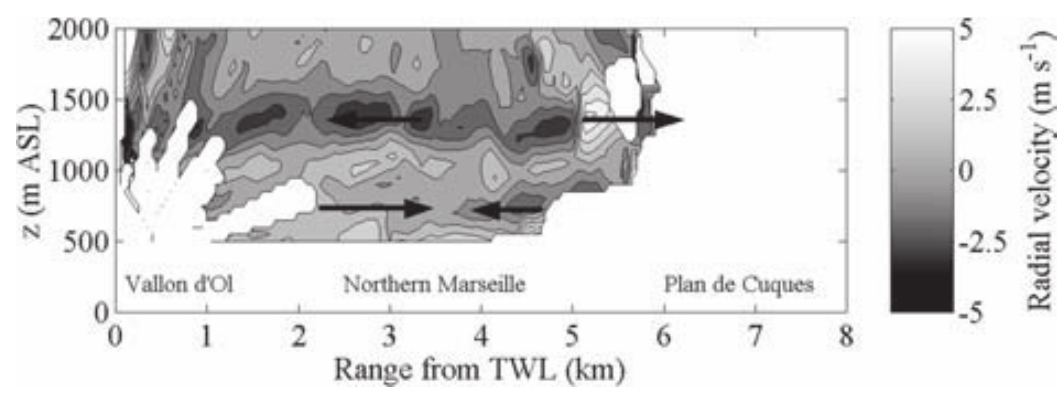

Figure 18. Vertical cross section of the radial velocity observed at Vallon Dol with the TWL pointing eastward towards land (azimuth $110^{\circ}$ ). Arrows indicate flow directions in the section. 

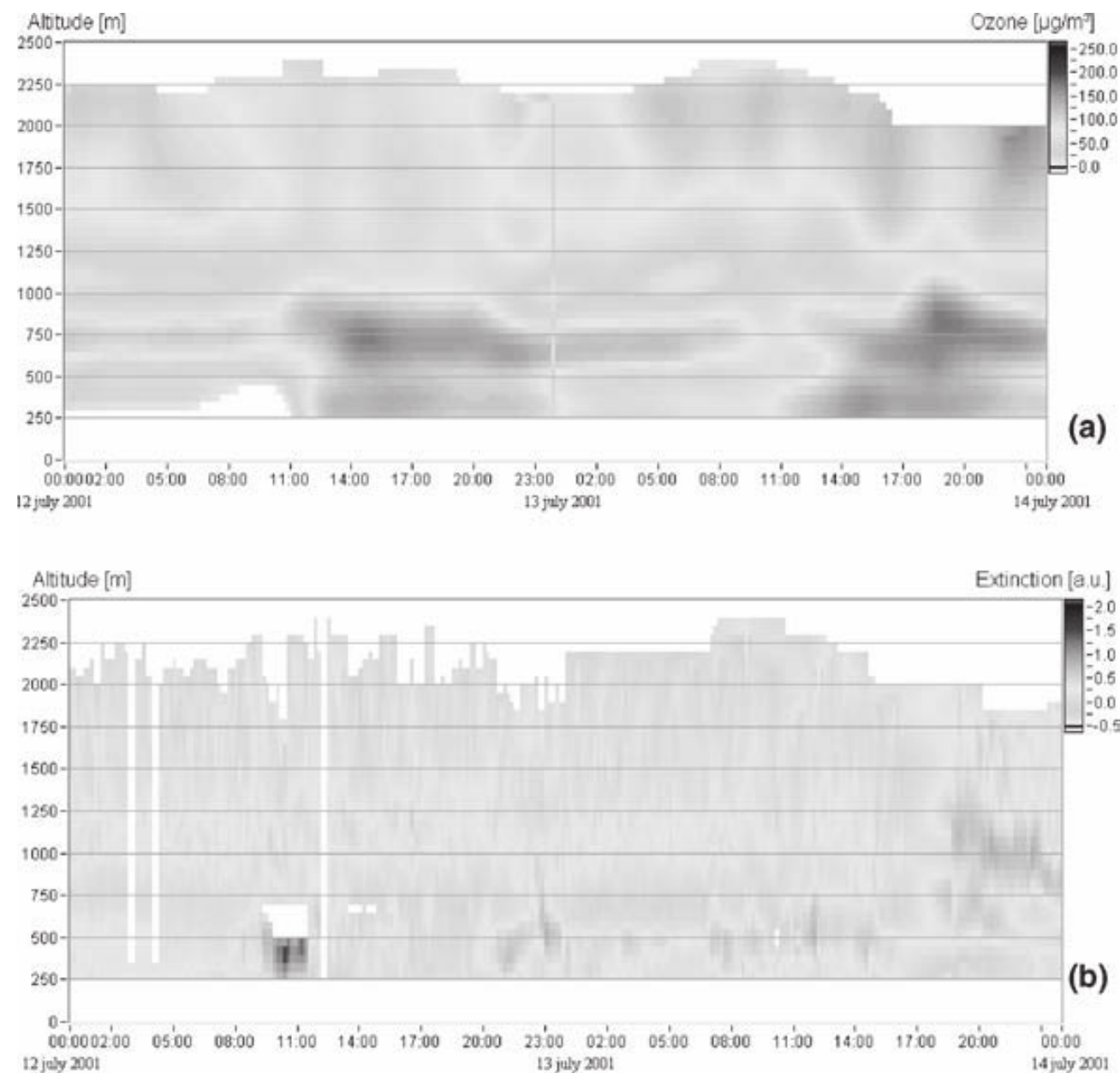

Figure 19. (a) Vertical profiles of ozone concentration, in $\mu \mathrm{g} \mathrm{m}^{-3}$, and (b) atmospheric extinction, in $\mathrm{km}^{-1}$, obtained with the stand-alone vertical ozone/aerosol lidar between July 12 and 14 at the Observatoire.

The ESCOMPTE set-up included an ozone and aerosol lidar (Elight, Ozone Profiler) at a station $60 \mathrm{~km}$ north of Marseille that was closed during the last week of the campaign. This stand-alone vertical ozone profiler was first moved to the OBS site (July 10-15) and then to the VAL site (July 1516), collocated on both sites with wind profilers. The objective was to obtain continuous observations of the urban boundary layer by measuring the vertical profiles of ozone concentration and extinction coefficient to retrieve the aerosol concentration and deduce the mixing height. The profiles ranged from 100 to $2500 \mathrm{~m}$ agl, with a spatial resolution better than $100 \mathrm{~m}$ and a time resolution of $3 \mathrm{~min}$. Figure 19 shows an example of the height-time section of ozone concentration and atmospheric extinction obtained between July 12 and 14 at the OBS site. During this period the meteorological conditions were cloud-free, high air temperature, and a steady westerly wind from July 12 to the late afternoon of July 13. The preliminary quality control on altitude ozone measurements suggest a global uncertainty of less than $15 \%$. The diurnal cycle of ozone concentration in the ABL shows a vertical 
stratification that is relatively permanent except in the convective late afternoon of the second day. Within this stratification pattern convection may be observed during the first day to average the ozone concentration up to $1000 \mathrm{~m}$. During both nights the surface ozone consumption (traffic, deposition) decreases the concentrations close to ground level, thus inducing a residual ozone layer at higher altitude, though still below the main stratification. It is interesting to note that the largest amount of aerosol is not systematically observed in the daytime polluted ABL (Figure 19b). During the late evening of July 13, the westerly wind decrease may be related to the vertical development of atmospheric extinction when convection processes become dominant.

Data obtained in the UV at $300 \mathrm{~nm}$ with the two Elight lidars, and those obtained in the IR at $10 \mu \mathrm{m}$ with the TWL, can be combined to evaluate the spectral dependency of aerosol scattering and the spatial distribution of the urban aerosol size spectrum. First results show different aerosol vertical stratification, which may be evidence of an aerosol size-height dependency within the urban boundary layer.

\subsection{Aircraft measurements}

Of the seven aircraft involved in the ESCOMPTE experiment, the Merlin IV (Météo France) performed six dedicated flights in the UBL with the aim of studying the variability of dynamic and thermodynamic properties by measuring turbulence along transects across the town (the aircraft equipment is described by Cros et al., 2004). The flight tracks are shown in Figure 20. Superimposed horizontal legs were performed at 3000, 1050, 750 and $500 \mathrm{~m}$ asl from turning points $\mathrm{C} 1$ to $\mathrm{C} 3$ and $\mathrm{C} 4$ to $\mathrm{C} 5$, in order to document conditions in two vertical planes crossing over the city centre.

Along the lower three legs, turbulence intensity was estimated from the local dissipation rates of turbulent kinetic energy (Figure 21), since the proximity of the sea-shore and the complex geometry, roughness and surface energy balance of the city, and the relief prohibited a classical computation of turbulence moments using the eddy covariance method. Furthermore lengthaveraged moments would have smoothed turbulence variability. Therefore the dissipation rate of turbulent kinetic energy was computed using a narrow frequency window around $3 \mathrm{~Hz}$ (circa $30-\mathrm{m}$ wavelength) and provided an indication of turbulence intensity with a $2-\mathrm{km}$ resolution, chosen to be close to the grid-mesh size of the mesoscale models. Figure 21 shows the flight of June 26, from 0930 to 1230 UTC, with a south to south-east wind: it shows low values of the dissipation rate over the sea, with a significant increase north of the Calanques ridge of hills. At all levels the values are highest north of $43.5^{\circ} \mathrm{N}$, while they show horizontal and vertical variability over the city 


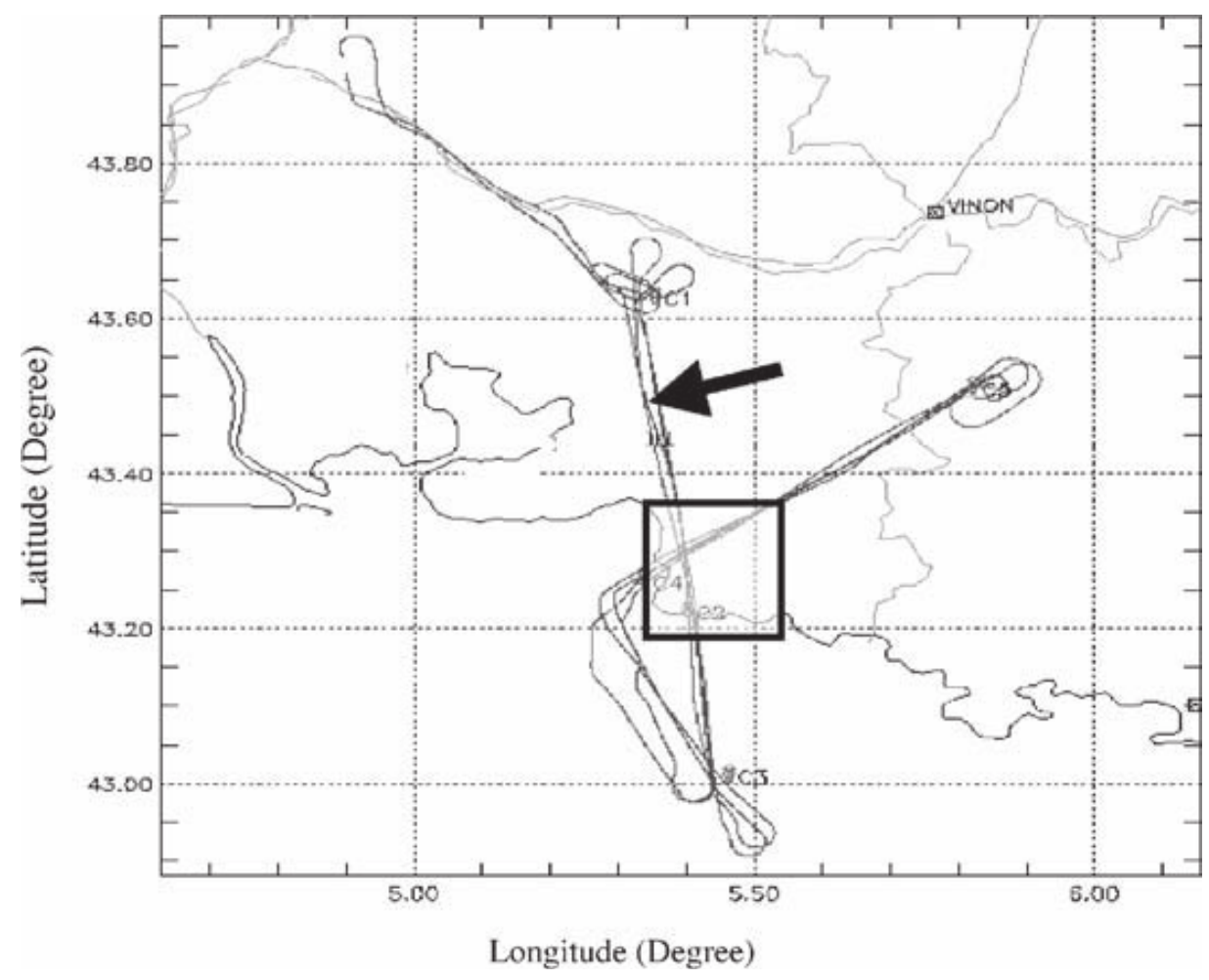

Figure 20. Horizontal flight track of the June 26 Merlin aircraft flight. The square corresponds approximately to the urbanized area. The arrow indicates the north-south track of the lower three legs used in the dissipation rate study (Figure 21).

and the Etoile ridge, revealing a varying ABL development to the north of the coast line.
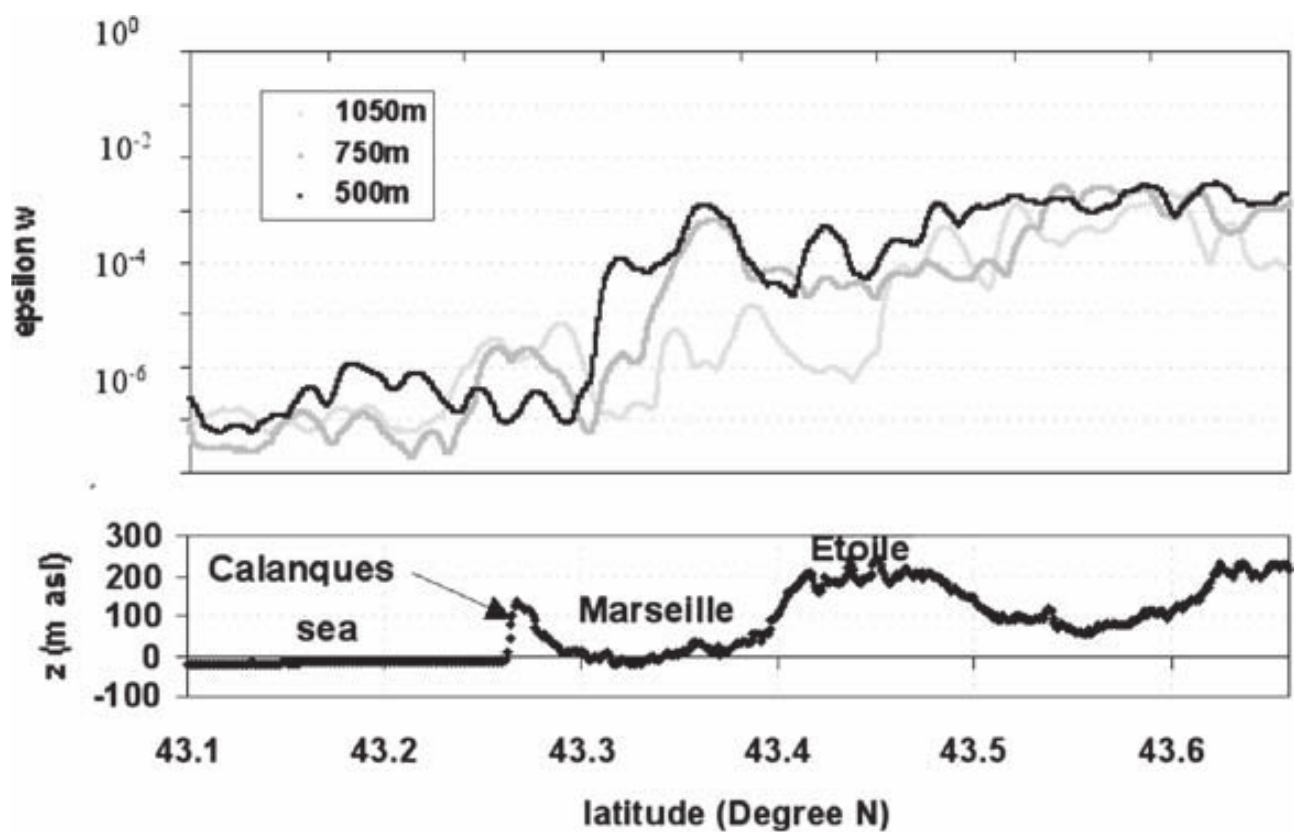

Figure 21. Dissipation rate of turbulent kinetic energy, $\varepsilon$, measured at the heights of 1050,750 and $500 \mathrm{~m}$ along the north-south flight legs shown in Figure 20. The relief of the terrain under the flight paths is shown in the lower panel. The flight paths are $63 \mathrm{~km}$ long, $11 \mathrm{~min}$ in duration; the city portion between the Calanques and Etoile ridges was traversed in $3 \mathrm{~min}$. 


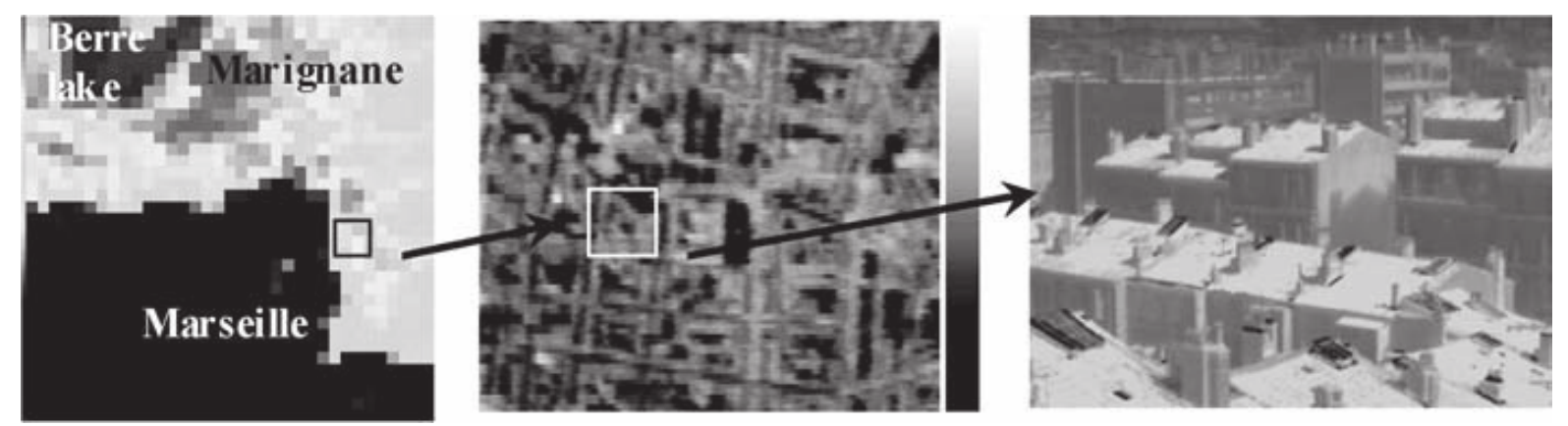

Figure 22. An illustration of the TIR multiscale images. Data for July 10, (left) NOAAAVHRR channel 4, (centre) airborne TIR Inframetrics 760 camera, and (right) ground-based with the FLIR ThermaCam SC500 scanner. Brightness temperature (without atmospheric correction) scales are $17.5-32.5,29.0-43.0$ and $20.0-50.0{ }^{\circ} \mathrm{C}$, respectively.

\section{Visible and Thermal Infrared Signatures over the City}

Remote sensing and satellite observation of urban areas may provide surface parameters such as land cover and structure, land-use, building density, height, etc. that can be used as input to urban energy exchange and atmospheric mesoscale models. Remote sensing can also provide surface variables such as albedo, emissivity and temperature at various spatial resolutions. An important component of the ESCOMPTE - UBL/CLU campaign was the multi-scale thermal remote observation of the Marseille urban area (Figure 22). The data acquired included satellite (AVHRR, ASTER), aircraft (Inframetrics 760 and PRT5 thermal sensors), and ground-based observations using both fixed and mobile infrared radiation thermometers (IRTs). Particular attention was paid to TIR directional effects due to the threedimensional structure of the urban canopy, in order to allow multi-scale assessment of urban surface temperature and its relation to canopy-level air temperature, and to provide data to validate surface-atmosphere exchange models.

\subsection{SATEllite DATA}

Images of land surface brightness temperature (LST) and NDVI were derived from the AVHRR data at $1.1-\mathrm{km}$ resolution. A temporal resolution of up to four images per day allowed analysis of diurnal variations, and the construction of statistical averages. For example, the image of July 10 (Figure 22) shows differences in brightness temperature of up to $5{ }^{\circ} \mathrm{C}$ between rural and urban-industrial areas of Marseille and Marignane. High temperatures closely follow the contours of built surfaces, and low ones those of marshlands, vegetated and mountain areas. Temperatures are highest $\left(34^{\circ} \mathrm{C}\right)$ in the industrial zone of Marignane, and lowest over coastal waters $\left(20^{\circ} \mathrm{C}\right)$ 


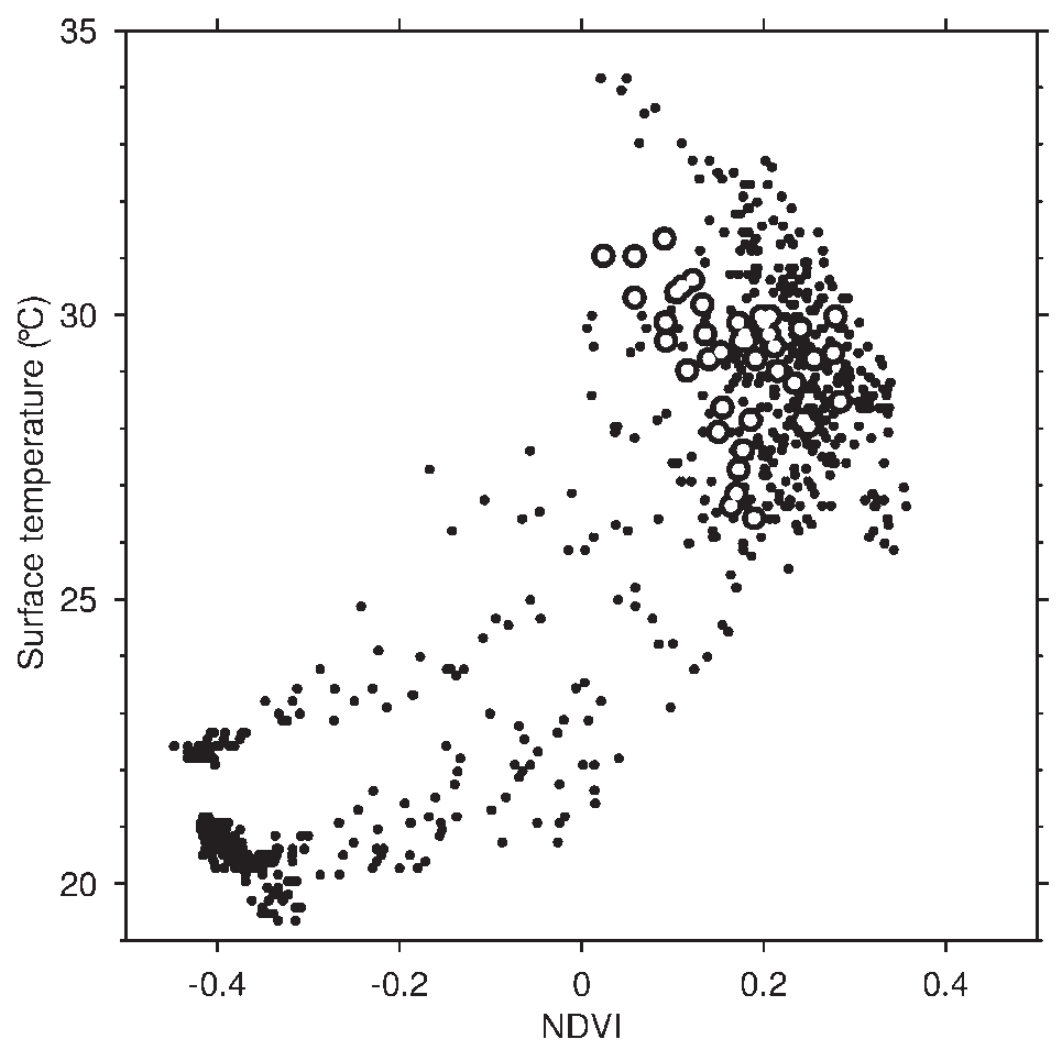

Figure 23. Scatter plot between afternoon NOAA-AVHRR LST and NDVI over the entire area in Figure 22 left (black dots), and over a subset of pixels near the city centre (white dots).

and the Etang de Berre $\left(22^{\circ} \mathrm{C}\right)$. In Marseille, surface temperatures reach $31{ }^{\circ} \mathrm{C}$ in the densely built-up areas, with small parks cooler by $1.5-3.5^{\circ} \mathrm{C}$. Temperatures are lower in residential areas $\left(29^{\circ} \mathrm{C}\right)$, due to their greater vegetation cover.

The NDVI was mapped from the NOAA AVHRR to analyse its relation to surface temperature. Figure 23 displays the scatter plot of surface temperature versus NDVI for the same AVHRR image. The dots with lowest temperatures (around $20{ }^{\circ} \mathrm{C}$ ) and negative NDVI correspond to water, the others to rural and urban areas. The white dots represent a $4 \times 15 \mathrm{~km}^{2}$ strip oriented from south-east to north-west over the city and suburbs of Marseille, and show strong negative correlation (slope -0.03) between surface temperature and NDVI. This confirms the well-known significance of vegetation in the partition of surface heat fluxes (Dousset, 1991; Grimmond and Oke, 2002; Dousset and Gourmelon, 2003).

Statistical averages of surface temperature and its diurnal cycle were constructed over the five stations shown on Figure 1. The largest temperature difference between stations OBS and VAL is $2{ }^{\circ} \mathrm{C}$ at night, and $3{ }^{\circ} \mathrm{C}$ in the afternoon. The amplitudes of the diurnal course are 15 and $15.5^{\circ} \mathrm{C}$ over stations STJ and OBS, respectively, $13.5^{\circ} \mathrm{C}$ over suburban stations VAL and GLM, and $13{ }^{\circ} \mathrm{C}$ over the urban station CAA nearest the sea. These are comparable to the air surface temperatures given in Section 5.2. Surface 
emissivities can be derived from ASTER imagery using the Temperature Emissivity Separation method of Gillespie et al. (1998); no results are given here.

The albedo of urban surfaces is assumed to be quite sensitive to sun-angle conditions due to building geometry, and relatively little is known about this effect. The NOAA-AVHRR imagery archived during this campaign provide atmosphere-corrected visible and near-IR reflectance data including a large range of sun angles and satellite-view conditions. These data can be used to evaluate the bi-directional reflectance distribution function over the different districts of Marseille as a first step to better knowledge of the sun-angle dependence of urban albedo.

\subsection{Aircraft DAta}

The thermal dataset includes airborne measurements: a TIR camera (INFRAMETRICS model 760, 7.5-13 $\mu \mathrm{m}$ spectral window) aboard a PA28 aircraft provided directional measurements, and a PRT5 Barnes radiometer $(8-14 \mu \mathrm{m})$ aboard the Merlin 4 aircraft provided nadir surface brightness temperature measurements during its flights over Marseille.

The TIR camera was equipped with $80^{\circ}$ wide-angle lenses and inclined about $20^{\circ}$ backward. Flying several flight lines that cross over the city provided TIR measurements in a $-60^{\circ}$ to $+60^{\circ}$ range of zenith view angles, and in all azimuth directions (Lagouarde et al., 2000). This enabled characterization of the TIR directional effect as the difference between oblique and nadir measurements of radiative surface temperature, similar to the "effective anisotropy' observed by Voogt and Oke (1997, 1998). Flights were performed at different times and dates (June 26, 29, July 10, and 12) over three contrasting parts of the urban area: the densely built-up city centre, a built/ vegetated mixture of small houses and gardens (St Barnabé suburb), and an ensemble of large, modern, slab-like buildings (La Rose suburb). An example of the first results for the city centre reveals an important 'hot spot' with temperature variations reaching an amplitude of $6{ }^{\circ} \mathrm{C}$ along the principal solar plane (Figure 24). Analysis of the whole dataset will allow evaluation of the combined effects of the solar illumination geometry (time of day) and the structure of the district on the position and intensity of the hot spot.

\subsection{GROUND-BASED DATA}

Stationary infrared thermometers were installed at three sites in the city centre. These were chosen to be representative of the characteristic street orientation, canyon geometry and surface materials of this district. Contin- 


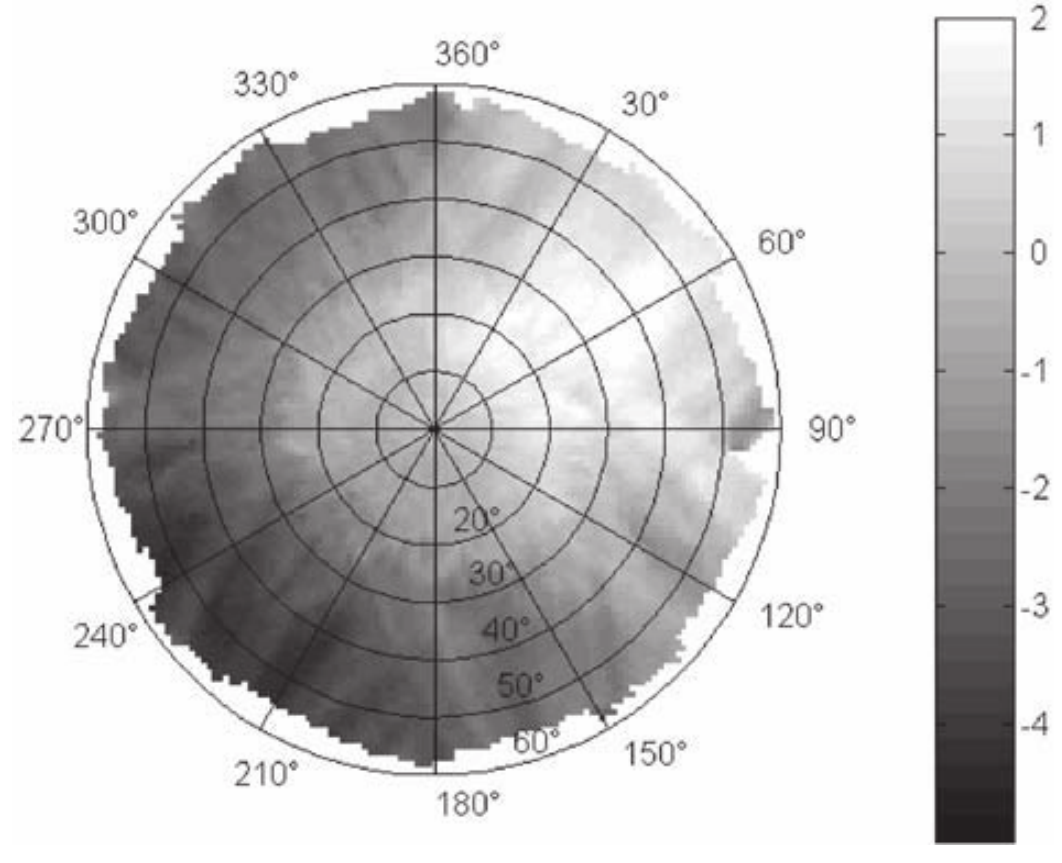

Figure 24. TIR directional effects measured over the city centre on July 10, 2001 between 1359 and 1428 UTC. The viewing angles are indicated by concentric circles for zenith and by the radius for azimuth. The hot spot corresponds to the direction opposite to the position of the Sun in the sky (azimuth $245.1^{\circ}$, zenith $35.6^{\circ}$ ). The scale of temperature difference from the nadir measurement is in ${ }^{\circ} \mathrm{C}$.

uous observations (15-min averages) were performed at each site over a 3 -week period using an array of Everest 4000 Series infrared transducers with $15^{\circ}$ and $60^{\circ}$ fields of view. Within a street canyon, infrared sensors monitored the surface temperatures of building walls and road surfaces; other sensors measured the temperatures of selected building roofs. These continuous observations (Figure 25) can be used to compute the 'complete surface

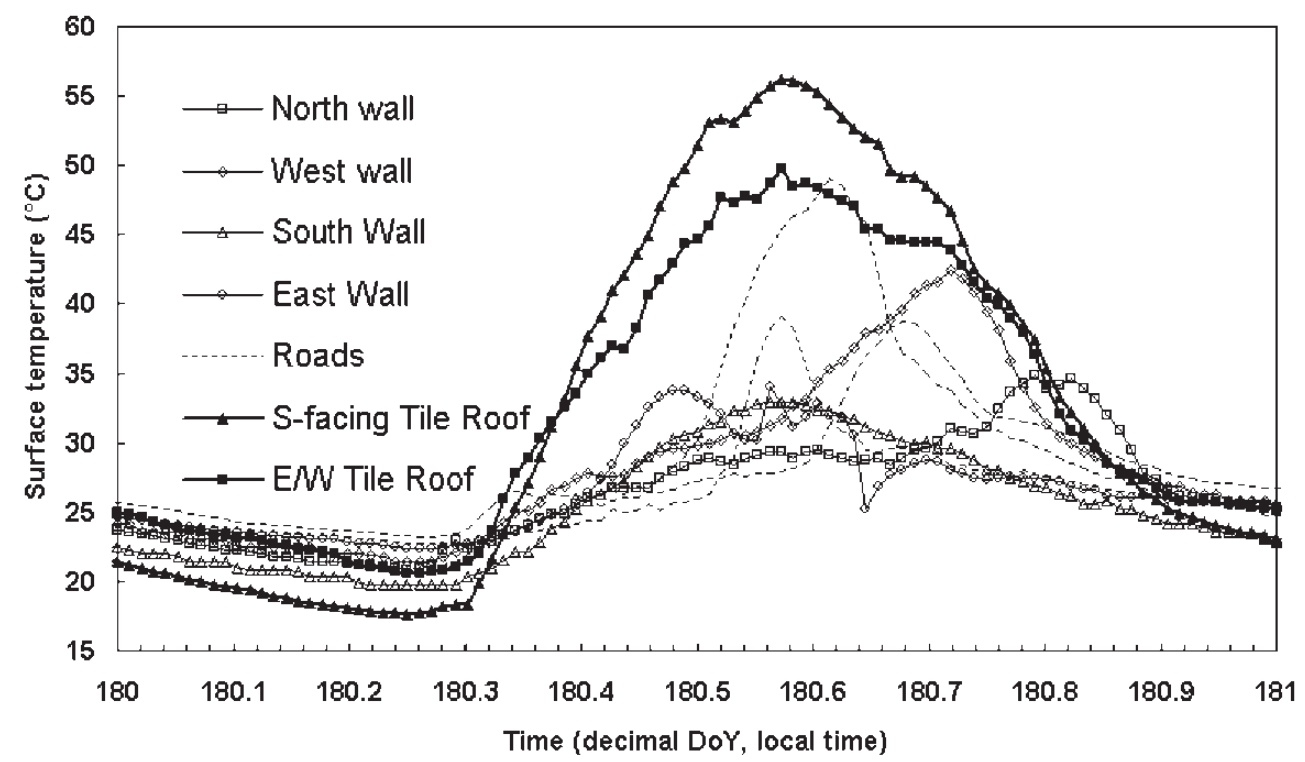

Figure 25. Time series of the surface temperatures of selected urban facets as observed by fixed infrared sensors (from Lagouarde et al., 2004). 


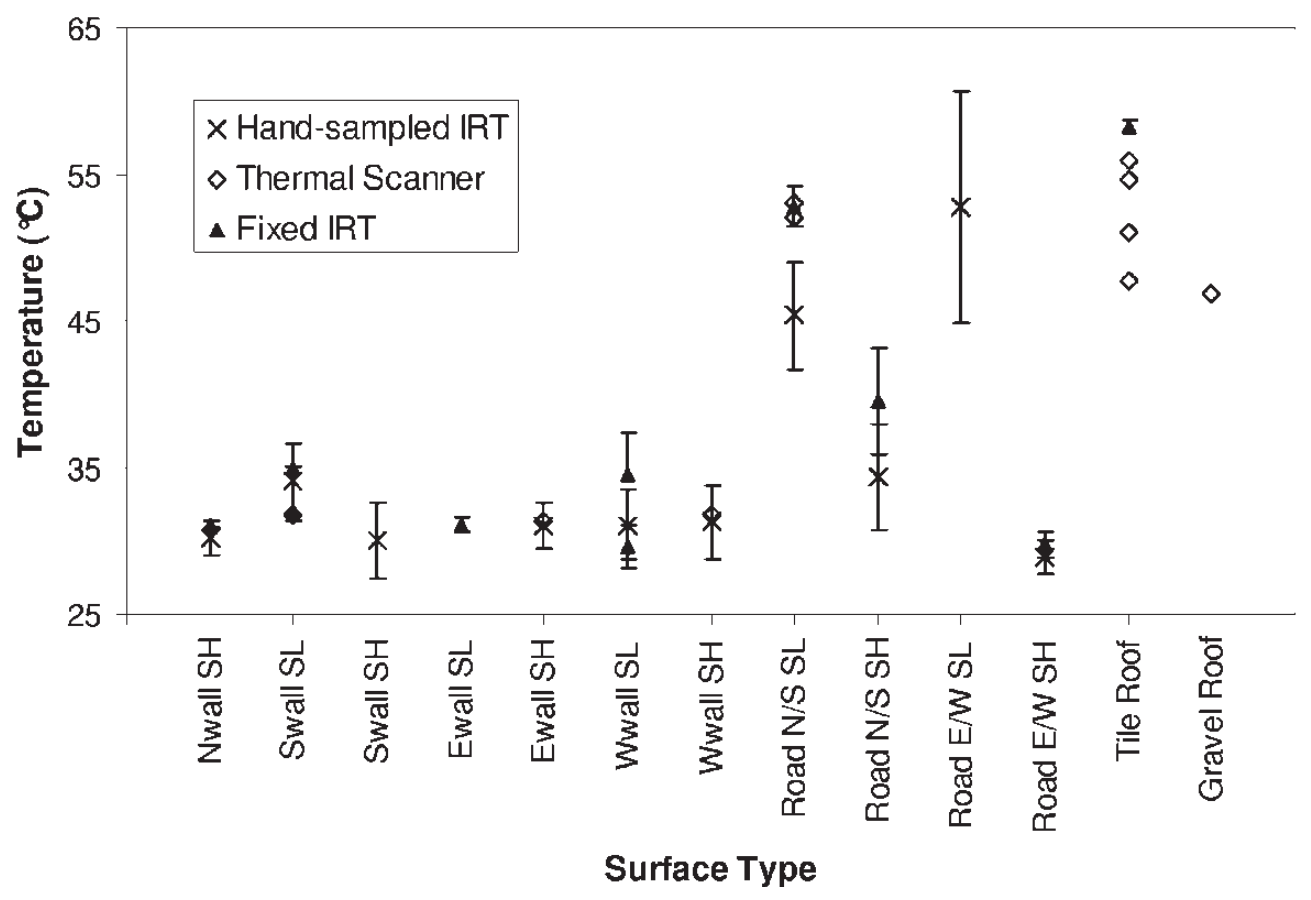

Figure 26. Composite plot of surface temperatures derived from the three observing systems in the downtown study area during the time of an aircraft overflight (June 26, 2001, 1340-1430 UTC). Symbols represent the mean value for the period. Error bars where plotted are one standard deviation for measurements made during the period.

temperature' of the urban surface (Voogt and Oke, 1997), and to support energy balance studies (Section 5) including assessment of the storage heat flux.

These fixed continuous measurements were supplemented by mobile sampling of canyon surface temperatures during the aircraft and satellite overflights, by surveys conducted on foot using hand-held infrared thermometers (Minolta/Land Cyclops Compac 3). Temperatures of the walls (including windows and façades) and the canyon floor (road and sidewalks) were observed. Additional annotations indicated whether the target surface was directly sunlit or in shade. Sampling was performed in teams of two and provided coverage of four street canyons (two in each of two orthogonal street directions) centred on the time of the over-flight. The results (Figure 26) show that, with the exception of the most directly irradiated wall, wall surfaces have fairly similar temperatures, and even the distinction between sunlit and shaded components of the walls is muted. This is probably because the relatively deep urban canyons at this site limit solar access, and the massive construction of the walls provides a large thermal mass to store heat, and thus offset rapid changes in surface temperature. These findings, and the similarity of building materials used in the study area, suggest that the fixed IRT measurements of wall temperatures made in select urban canyons can be considered to be reasonably representative of the study area. Road surface temperatures (both sunlit and shaded components) show the greatest variability because of rapid 


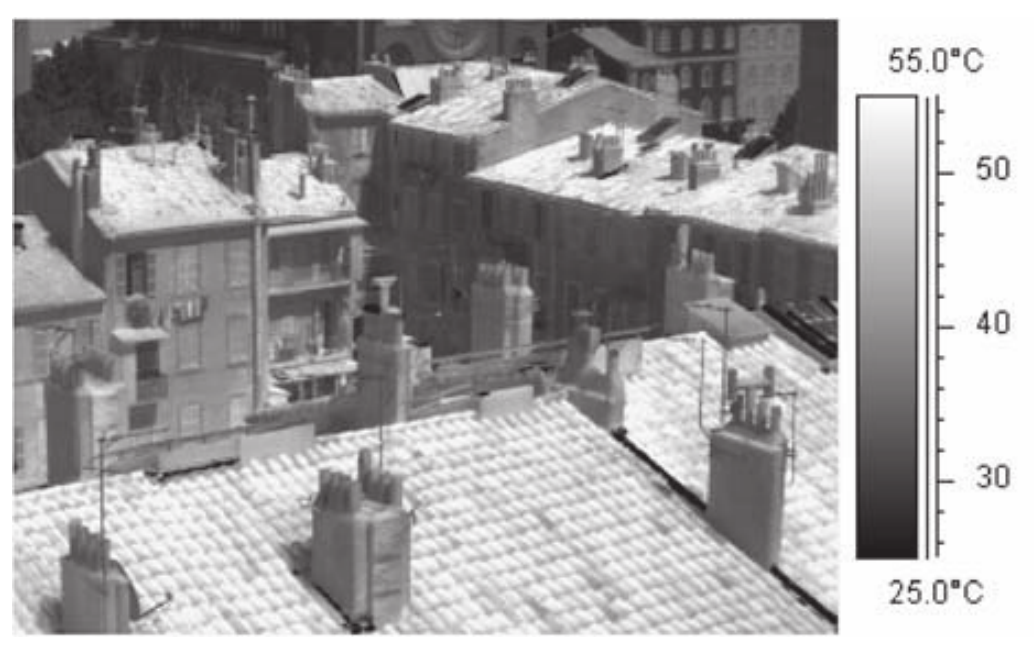

Figure 27. Thermal image of a portion of the central city study area.

temporal changes in the spatial pattern of sunlit and shaded areas. There are significant differences in road surface temperature with street orientation that may be important to the pattern of urban thermal anisotropy. This variability is more easily captured by the mobile and thermal scanner data than by the fixed IRT data that monitor a spatial average across the road surface. Roof temperature variability is also large mainly due to variations in the slope and aspect of the largely tile-covered roofs.

A thermal scanner (FLIR SC500) was used during the over-flights to provide detailed surface temperature information for the wide range of surface types and orientations visible from the roof-top of a tall building (Figure 27). Temperatures from selected surfaces on these images are extracted using image analysis to supplement the fixed and mobile instrument arrays at these times (Figure 26). This provides additional comparative data for the assessment of model output, and provides input data for models of the directional variation of the upwelling longwave radiative flux over urban areas.

\subsection{Modelling}

Two modelling approaches are followed, both based on the use of 3-D models of urban fragments (Figure 28) built using the BDTopo data base provided by IGN. The first uses the SOLENE model (Vinet and Groleau, 2000), which computes the energy balances of all facets of the urban 3-D surface. Visible and TIR radiative balances are computed for every surface facet and simplified equations for convective exchanges in the air and conduction through the walls allow the turbulent sensible heat flux and heat storage to be estimated (Groleau et al., 2003). SOLENE can be used to produce surface temperature fields, such as the block in the city centre illustrated in Figure 29. Possible applications include estimation of upwelling 


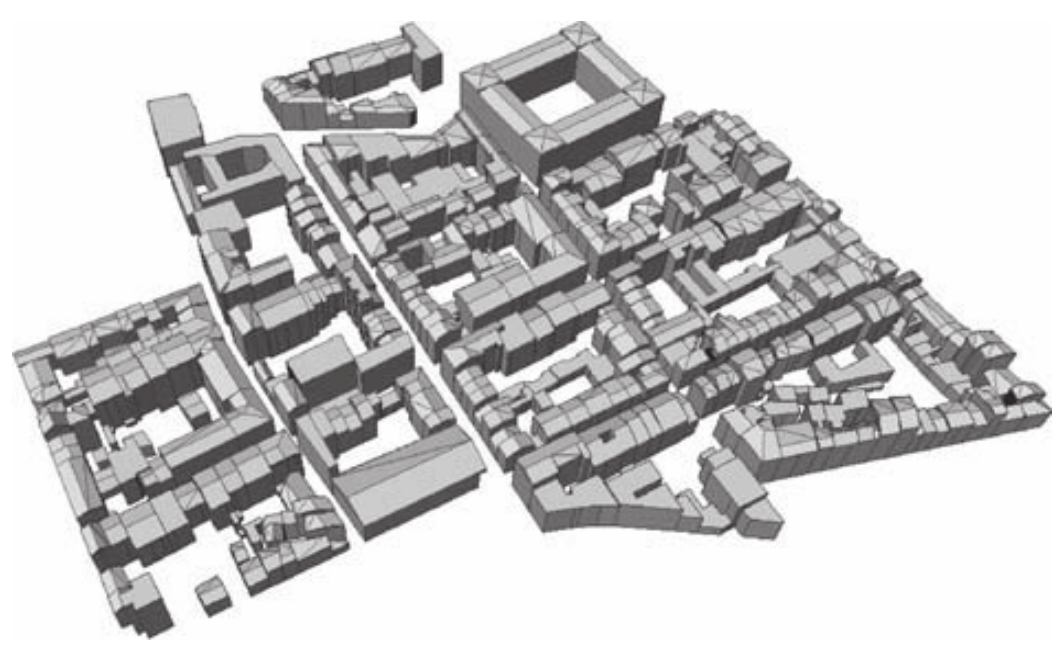

Figure 28. Three-dimensional representation of the city centre around the Prefecture and CAA site. The horizontal distance between left and right limits is $430 \mathrm{~m}$.

longwave fluxes, or the simulation of directional measurements of the surface temperature of the urban canopy.

The second approach is a simplified one specifically devoted to modelling angular variations of TIR. It is based on the assumption that six average component temperatures may be defined, for sunlit or shaded roofs, walls and ground. Directional radiative temperatures are computed by combining them with the proportions of sunlit and shadowed areas determined for all azimuth and zenith viewing angles from images generated with Pov-Ray
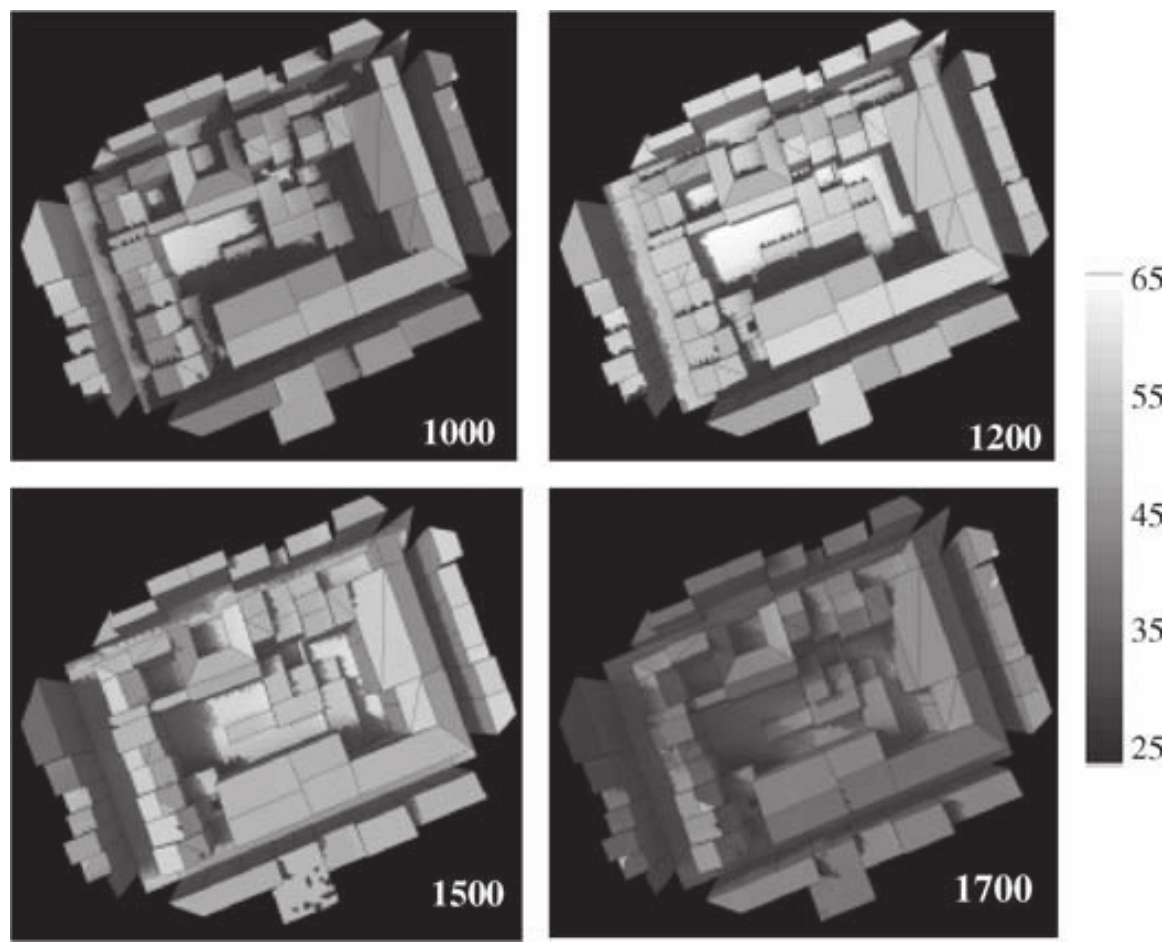

Figure 29. Simulation of the surface temperatures of an urban block in the city centre quarter using the SOLENE model at different times of the day (1000, 1200, 1500, and 1700 UTC, June 26). Temperature scale in ${ }^{\circ} \mathrm{C}$. 
software and the 3-D model (Lagouarde et al., 2002a). This approach is tested because it is potentially attractive as an inversion technique and should help to define the combined configurations of TIR measurements best suited to the retrieval of the constituent temperatures of thermal scenes.

\section{Conclusions}

We have described the overall design, experimental set-up and initial results of the Marseille Urban Boundary-Layer observation and modelling project. UBL/CLU benefited significantly from the larger-scale observational campaign in the Marseille-Berre region undertaken as part of ESCOMPTE. This arrangement permitted concurrent monitoring using air and ground-based remote-sensing systems, with embedded 'local' and 'regional' sensor arrays, together with surface micrometeorological flux stations at multiple sites. This allows intercomparison of different methods/approaches and the analysis of urban microscale and local-scale processes in the context of larger scale observations (especially intermediate between the local and synoptic scales).

Good agreement was observed between scintillometer and eddy covariance sensible heat flux measurements, illustrating the potential of scintillometry for urban areas where spatial heterogeneity is large. Moreover, sensible heat fluxes were simulated well by the linked TEB/ISBA model with positive sensible heat flux at night and the correct daily cycle of heat storage both correctly simulated.

The different effects of the mistral and land-breeze and sea-breeze wind regimes on air temperature and humidity patterns in Marseille were documented. For mistral conditions the specific humidity is homogeneous over the whole urban area, but the average daily course reveals a decrease in moisture, a signature of air mass drying during these windy conditions. For sea-breeze conditions, a moisture gradient along the breeze direction is observed at all times, and there is an increase of mean humidity from morning to evening. During the land/sea-breeze regime the periods of weakest flow were associated with the largest nocturnal urban heat islands.

The 3-D structure of the urban boundary layer was documented with the help of airborne measurements, radiosondes, and remote sensing with lidars, sodars and a UHF radar. The morning ascent of the atmospheric boundarylayer top was shown to culminate at a height of $750 \mathrm{~m} \mathrm{agl}$ in the early afternoon, and under well-developed sea-breeze conditions subsequently to collapse. A large fraction of the heat flux is consumed to warm the relatively cool and humid marine air advected inland, at the expense of ABL vertical development. The lidars reveal complex regional flow patterns, with the sea breeze moving inland in a $1-\mathrm{km}$ deep layer, approximately $90^{\circ}$ from the coastline, with a return flow aloft between 1 and $1.5 \mathrm{~km}$ asl. In the eastern 
suburbs of Marseille, a reverse flow in the opposite direction may also occur. This may originate from an urban breeze induced by the thermal gradient between Marseille and the surrounding rural area.

Remote sensing and satellite observations have been used to provide surface parameters such as land cover and structure, land use, building densities and heights, and also important insight into Marseille's surface thermal regime. The integration of geographical, meteorological, thermodynamic, dynamic, and chemical observations in a unique comprehensive database offers a great opportunity for in-depth analysis of non-linear coupling between atmospheric processes in urban areas.

\section{Acknowledgements}

Through the cooperative projects CLU and TUE, the UBL/CLU-ESCOMPTE experiment was funded by the CNRS programmes for atmospheric dynamics (PATOM) and remote sensing from space (PNTS). Bernard Cros and the ESCOMPTE committees deserve warm thanks. As an associate project it also benefited from ESCOMPTE funding. Part of the funding of the North American participants was provided by the National Science Foundation (NSF), the Natural Sciences and Engineering Research Council of Canada (NSERC) and the Canadian Foundation for Climate and Atmospheric Science (CFCAS). The BDTopo urban database was provided by the Institut Géographique National (IGN). The RASS-sodar profiler and one sonic anemometer were made available by Alliance Technologies, and the stand-alone Vertical Ozone Profiler by Elight Laser System GmbH. Trade and company names are given for the benefit of the reader and do not imply endorsement of the product or company by the authors. The authors would like to thank A. Delaval, G. Beffrey, M. Chiriaco, C. Boitel, P. Delville, and B. Romand for their assistance with the TWL; F. Parmigiani (University of Modena) who collected the NOAA-AVHRR images; P. Jackson and C. Walsh for field assistance at the CAA site; J. Jagoury, Y. Lorin and D. Gaudin (ECN), Y. Tétard and Y. Queveau (CSTB); and Siriatech (Villeneuve d'Ascq, France) for assistance and support.

The project benefited from two major cooperative exchange arrangements: SATURN, the urban sub-project of EUROTRAC-2 (Moussiopoulos, 2003) and COST action 715 (Piringer et al., 2002; Fisher et al., 2001).

\section{References}

Anquetin, S., Chollet, J. P., Coppalle, A., Mestayer, P. and Sini, J. F.: 1999, 'The Urban Atmosphere Model SUBMESO', in P. M. Borrel and P. Borrel (eds.), EUROTRAC Symposium '98, WIT Press Southampton, pp. 750-757. 
Armand, M.: 1995, Télédétection, urbanisme et aménagement, Cahiers Pédagogiques du GDTA, GDTA, Toulouse, 150 pp.

Arnfield, J. A.: 2003, 'Two Decades of Urban Climate Research: A Review of Turbulence Exchanges of Energy and Water, and the Urban Heat Island', Int. J. Climatol. 23, 1-23.

ASHRAE: 1981, ASHRAE Handbook 1981, Fundamentals, American Society of Heating, Refrigerating and Air-conditioning Engineers, Atlanta.

Bock, O., Doerflinger, E., Masson, F., Walpersdorf, A., Van-Baelen, J., Tarniewicz, J., Troller, M., Somieski, A., Geiger, A., and Bürki, B.: 2004, 'GPS Water Vapor Project Associated with the ESCOMPTE Programme: Description and First Results of the Field Experiment', Phys. Chem. Earth 29, 149-157.

Bottema, M.: 1997, 'Urban Roughness Modelling in Relation to Pollutant Dispersion', Atmos. Environ. 31, 3059-3075.

Coppalle, A. and Talbaut, M.: 2002, 'Observations of the Wind Speed Profile Close to the Ground Using a Mini-Sodar, Results of the UBL/CLU-ESCOMPTE Campaign over Marseille City', in Proceedings, 4th Conference on Urban Environment, Norfolk, U.S.A., 20-24 May 2002, American Meteorological Society, 45 Beacon St., Boston, MA, pp. 211212.

Cros, B., Durand, P., Cachier, H., Drobinski, Ph., Fréjafon, E., Kottmeïer, C., Perros, P. E., Ponche, J. L., Robin, D., Saïd, F., Toupance, G., and Wortham, H.: 2004, 'The ESCOMPTE Program: An Overview', Atmos. Res., 69, 241-279.

Dabas, A., Drobinski, P., and Flamant, P. H.: 1999, 'Adaptive Filters for Frequency Estimate of Heterodyne Doppler Lidar Returns: Recursive Implementation and Quality Control', $J$. Atmos. Oceanic Tech. 16, 361-372.

De Bruin, H. A. R., Van den Hurk, B. J. J. M., and Kohsiek, W.: 1995, 'The Scintillation Method Tested over a Dry Vineyard Area', Boundary-Layer Meteorol. 76, 25-40.

Diday, E., Lemaire, J., Pouget, J., and Testu, F.: 1982, Eléments d'analyse de données, Dunod - Bordas Editions, Paris, France, 464 pp.

Dousset, B.: 1991, 'Surface Temperature Statistics over Los Angeles: The Influence of Land Use', in Proceedings of International Geophysics and Remote Sensing Symposium 91, Helsinki, Finland, July 1991, I.E.E.E., pp. 367-371.

Dousset, B. and Gourmelon, F.: 2003, 'Satellite Multi-Sensor Data Analysis of Urban Surface Temperatures and Landcover', ISPRS J. Photogram Remote Sens. 58, 43-54.

Drobinski, P., Brown, R. A., Flamant, P. H., and Pelon, J.: 1998, 'Evidence of Organised Large Eddies by Ground-Based Doppler Lidar, Sonic Anemometer and Sodar', BoundaryLayer Meteorol. 88, 343-361.

Drobinski, P., Dabas, A. M., Delville, P., Flamant, P. H., Pelon, J., and Hardesty, R. M.: 1999, 'Refractive Index Structure Parameter in the Planetary Boundary Layer: A Comparison of Measurements Taken by a $10.6 \mu \mathrm{m}$-Coherent Lidar, a $0.9 \mu \mathrm{m}$-Scintillometer and In Situ Sensors', Appl. Opt. 38, 1648-1656.

Drobinski, P., Dabas, A. M., Haeberli, C., and Flamant, P. H.: 2001, 'On the Small-Scale Dynamics of Flow Splitting in the Rhine Valley during a Shallow Foehn Event', BoundaryLayer Meteorol. 99, 277-296.

Drobinski, P., Haeberli, C., Richard, E., Lothon, M., Dabas, A. M., Flamant, P. H., Furger, M., and Steinacker, R.: 2003, 'Scale Interaction Processes during MAP-IOP 12 South Foehn Event in the Rhine Valley', Quart. J. Roy. Meteorol. Soc. 129, 729-754.

Dupont, S., Guilloteau, E., and Mestayer, P. G.: 2000, 'Energy Balance and Surface Temperatures of Urban Quarters', in Proceedings, 3rd Conference on Urban Environment, Davis, CA, 14-18 August 2000, American Meteorological Society, 45 Beacon St., Boston, MA, pp. 149-150. 
EDF and Atelier du patrimoine de la ville de Marseille: 1983, 'Le Bâti ancien a Marseille', coll. Connaissance de l'habitat existant, EDF, DER, Paris, France (In french), 144 pp.

Fisher, B. E. A., Kukkonen, J., and Schatzmann, M.: 2001, 'Meteorology Applied to Urban Air Pollution Problems COST 715', in Proceedings 6th International Conference on Harmonisation within Atmospheric Dispersion Modelling for Regulatory Purposes, 11-14 October, 1999, Rouen, France, Int. J. Environ. Pollut. 16, 560-570.

Gillespie, A., Rokugawa, S., Matsunaga, T., Cothern, J. S., Hook, S., and Kahle, A. B.: 1998, 'A Temperature and Emissivity Separation Algorithm for Advanced Spaceborne Thermal Emission and Reflection Radiometer (ASTER) Images'. IEEE Trans. Geosci. Remote Sens. 36, 1113-1126.

Grimmond, C. S. B.: 1992, 'The Suburban Energy Balance: Methodological Considerations and Results for a Mid-Latitude West Coast City under Winter and Spring Conditions', Int. J. Climatol. 12, 481-497.

Grimmond, C. S. B. and Oke, T. R.: 1999, 'Heat Storage in Urban Areas: Local-Scale Observations and Evaluation of a Simple Model', J. Appl. Meteorol. 38, 922-940.

Grimmond, C. S. B. and Oke, T. R.: 2002, 'Turbulent Heat Fluxes in Urban Areas: Observations and a Local-Scale Urban Meteorological Parameterization Scheme (LUMPS)', $J$. Appl. Meteorol. 41, 792-810.

Grimmond, C. S. B., Salmond, J., Offerle, B. D., and Oke, T. R.: 2002, 'Local-Scale Surface Flux Measurements at a Downtown Site in Marseille during the ESCOMPTE Field Campaign', in Proceedings, 4th Conference on Urban Environment, Norfolk, U.S.A., 20-24 May 2002, American Meteorological Society, 45 Beacon St., Boston, MA, pp. 21-22.

Groleau, D., Fragnaud, F., and Rosant, J- M.: 2003, Simulation of the Radiative Behaviour of an Urban Quarter of Marseille with the SOLENE Model', in CD Proceedings, 5th International Conference on Urban Climate, Lodz, Poland, 1-5 September 2003, O.19.3, 4 pp.

Irvine, M., Lagouarde, J. -P., Bonnefond, J. -M., Grimmond, C. S. B., and Oke, T. R.: 2002, 'Spectral Analyzes of Optical Scintillation: Refraction and Absorption Components in a Urban Zone', in Proceedings, 4th Conference on Urban Environment, Norfolk, U.S.A., 20 24 May 2002, American Meteorological Society, 45 Beacon St., Boston, MA, pp. 217 218.

Jacoby-Koaly, S., Campistron, B., Bernard, S., Bénech, B., Ardhuin-Girard, F., Dessens, J., Dupont, E., and Carissimo, B.: 2002, 'Turbulent Dissipation Rate in the Boundary Layer via UHF Profiler Doppler Spectral Width Measurements', Boundary-Layer Meteorol. 103, 361-389.

Lafore, J., Stein, J., Ascencio, N., Bougeault, P., Ducrocq, V., Duron, J., Fischer, C., Héreil, P., Mascart, P., Masson, V., Pinty, J. P., Redelsperger, J. L., Richard, E., and Vila-Guerau de Arellano, J.: 1998, 'The Meso-NH Atmospheric Simulation System. Part I: Adiabatic Formulation and Control Simulations', Ann. Geophys. 16, 90-109.

Lagouarde, J. P., Ballans, H., Moreau, P., Guyon, D., and Coraboeuf, D.: 2000, 'Experimental Study of Brightness Surface Temperature Angular Variations of Maritime Pine (Pinus Pinaster) Stands', Remote Sens. Environ. 72, 17-34.

Lagouarde, J.-P., Moreau, P., Solliec, F., Groleau, D., Irvine, M., Bonnefond, J.-M., and voogt J.: 2002a, 'Etude expérimentale et modélisation des effets directionnels dans l'IRT en zone urbaine', in Proceedings Atelier de Modélisation de l'Atmosphère 2002, Météo France, Toulouse, 17-19 December 2002, Meteo France, Avenue Gustave Coriolis, Toulouse, France, pp. 111-114.

Lagouarde, J. -P., Irvine, M., Bonnefond, J. -M., Grimmond, C. S. B., Long, N., Oke, T. R., Salmond, J., and Offerele, B.: 2002b, 'Sensible Heat Flux Estimated over the City of Marseille, Using a LAS Scintillometer', in Proceedings, 4th Conference on Urban Envi- 
ronment, Norfolk, U.S.A., 20-24 May 2002, American Meteorological Society, 45 Beacon St., Boston, MA, pp. 215-216.

Lagouarde, J. -P., Moreau, P., Irvine, M., Bonnefond, J. -M., Voogt, J., and Solliec, F.: 2004, 'Airborne Experimental Measurements of the Angular Variations in Surface Temperature over Urban Areas: Case Study of Marseille (France)', Remote Sens. Environ., in press

Larsen, S. E., Edson, J. B., Fairall, C. W., and Mestayer, P. G.: 1993, 'Measurement of Temperature Spectra by a Sonic Anemometer', J. Atmos. Oceanic Tech. 10, 345-354.

Lemonsu, A. and Masson, V.: 2002, 'Simulation of a Summer Urban Breeze over Paris'. Boundary-Layer Meteorol. 104, 463-490.

Lemonsu, A., Grimmond, C. S. B., and Masson, V.: 2004, 'Modelling the Surface Energy Balance of an Old Mediterranean City Core', J. Appl. Meteorol. 43, 312-327.

Long, N.: 2003, 'Analyses morphologiques et aérodynamiques du tissus urbain: Application à la micro-climatologie de marseille pendant la campagne ESCOMPTE', Doctoral thesis (in French), Université des Sciences et Techniques de Lille, France, 297 pp.

Long, N., Kermadi, S., Kergomard, C., Mestayer, P. G., and Trébouet, A.: 2003a, 'Urban Cover Modes and Thermodynamic Parameters from Urban Data Base and Satellite Data: A Comparison for Marseille during ESCOMPTE', in CD Proceedings, 5th International Conference on Urban Climate, Lodz, Poland, 1-5 September 2003, P.8.3 (4 pp.).

Long, N., Mestayer, P., and Kergomard, C.: 2003b, 'Urban Database Analysis for Mapping Morphology and Aerodynamic Parameters: The Case of St Jerome Sub-Urban Area, in Marseille during ESCOMPTE', in CD Proceedings, 5th International Conference on Urban Climate, Lodz, Poland, 1-5 September 2003, O.31.3 (4 pp.).

Long, N., Mestayer P. G., and Kergomard, C.: 2002, 'Development of Software to Describe the City Morphology and to Compute Aerodynamic Parameters from an Urban Data Base', in Proceedings, 4th Conference on Urban Environment, Norfolk, U.S.A., 20-24 May 2002, American Meteorological Society, 45 Beacon St., Boston, MA, pp. 31-32.

Macdonald, R. W., Griffiths, R. F., and Hall, D. J.: 1998, 'An Improved Method for the Estimation of Surface Roughness of Obstacle Arrays', Atmos. Environ. 32, 1857-1864.

Masson, V.: 2000, 'A Physically-Based Scheme for the Urban Energy Budget in Atmospheric Models', Boundary-Layer Meteorol. 98, 357-397.

Masson, V., Grimmond, C. S. B., and Oke, T. R.: 2002: 'Evaluation of the Town Energy Balance (TEB) Scheme with Direct Measurements from Dry Districts in Two Cities', $J$. Appl. Meteorol. 41, 1011-1026.

McAneney, K. J., Green, A. E., and Astill, M. S.: 1995, 'Large-Aperture Scintillometry: The Homogeneous Case'. Agric. For. Meteorol. 76, 149-162.

Mestayer, P. G.: 1996, 'Development of the French Communal Model SUBMESO for Simulating Dynamics, Physics and Photochemistry of the Urban Atmosphere', in P. M. Borrell, P. Borrel, T. Cvitas, K. Kelly, and W. Seiler (eds.), EUROTRAC Symposium'96, 25-29 March 1996, Garmisch-Partenkirchen, Germany, Computational Mechanics Public., Southampton, pp. 539-544.

Mestayer, P. G.: 1998, 'Urban Scale Models', in J. Fenger, O. Hertel, and F. Palmgren (eds.), Urban Air Pollution - European Aspects, Kluwer Academic Publishers, Dordrecht, pp. 197222.

Mestayer, P. G. and Anquetin, S.: 1994, 'Climatology of Cities', in A. Gyr and F.-S. Rys (eds.), Diffusion and Transport of Pollutants in Atmospheric Mesoscale Flow Fields, ERCOFTAC Series, Kluwer Academic Publishers, Dordrecht, pp. 165-189.

Mestayer, P. and Durand, P.: 2002, 'The UBL/CLU-Escompte Experiment: Description and First Results', in Proceedings, 4th Conference on Urban Environment, Norfolk, USA, 20-24 May 2002, American Meteorological Society, 45 Beacon St., Boston, MA, pp. 19-20. Moussiopoulos, N. (ed.): 2003, Air Quality in Cities, Springer-Verlag, Berlin, 298 pp. 
Noilhan, J. and Planton, S.: 1989, 'A Simple Parameterization of Land Surface Processes for Meteorological Models'. Mon. Wea. Rev. 117, 536-549.

Ohashi, Y. and Kida, H.: 2002, 'Numerical Experiments on the Weak-Wind Region Formed Ahead of the Sea-Breeze Front', J. Meteorol. Soc. Jpn. 80, 519-527.

Oke, T. R.: 1987, 'Boundary Layer Climates', 2nd edn., Methuen, London, 435 pp.

Oke, T. R.: 1988, 'The Urban Energy Balance', Progr. Phys. Geog. 12, 471-508.

Oke, T. R.: 1998, 'Observing Urban Weather and Climate', WMO Technical Conference on Meteorological and Environmental Instruments and Methods of Observation, WMO/TD No. 877, World Meteorological Organisation, Geneva, pp. 1-8.

Pigeon, G., Lemonsu, A., Durand, P., and Masson, V.: 2002 'Urban Surface Network in Marseille: Network Optimisation Using Numerical Simulations and Results', in Proceedings, 4th Conference on Urban Environment, Norfolk, U.S.A., 20-24 May 2002, American Meteorological Society, 45 Beacon St., Boston, MA, pp. 23-24.

Piringer, M., Grimmond, C. S. B., Joffre, S. M., Mestayer, P. G., Rotach, M. W., Baklanov, A., De Ridder, K., Ferreira, J., Guilloteau, E., Karppinen, A., Martilli, A., Masson, V., Middleton, D. R., and Tombrou, M.: 2002, 'Investigating the Surface Energy Budget in Urban Areas - Recent Advances and Future Needs'. Water Air Soil Pollut.: Focus 2, 1-16.

Raupach, M. R.: 1994, 'Simplified Expressions for Vegetation Roughness Length and Zeroplane Displacement Height as Functions of Canopy Height and Area Index', BoundaryLayer Meteorol. 71, 211-216.

Raupach, M. R., Thom, A. S., and Edwards, I.: 1980, 'A Wind Tunnel Study of Turbulent Flow Close to Regularly Arrayed Rough Surfaces’, Boundary-Layer Meteorol. 18, 373-397.

Roberts, S. M., Oke, T. R., Voogt, J. A., Grimmond, C. S. B., and Lemonsu, A.: 2003, 'Energy Storage in a European City Center'. in CD Proceedings, 5th International Conference on Urban Climate, Lodz, Poland, 1-5 September 2003,. O.12.1 (4 pp.).

Rotach, M. W., Fisher, B., and Piringer, M.: 2002, 'COST 715 Workshop on Urban Boundary Layer Parameterizations', Bull. Amer. Meteorol. Soc. 83, 1501-1504.

Schmid, H. P.: 1997, 'Experimental Design for Flux Measurements: Matching Scales of Observations and Fluxes', Agric. For. Meteorol. 87, 179-200.

Vachon, G., Louka, P., Rosant, J. -M., Mestayer, P. G., and Sini, J. -F.: 2002, 'Measurements of Traffic-Induced Turbulence within a Street Canyon during the Nantes '99 Experiment', Water Air Soil Pollut.: Focus 2 (5-6), 127-140.

Vinet, J. and Groleau, D.: 2000: 'La modélisation des transferts radiatifs dans le logiciel SOLENE. Applications au microclimat urbain et au confort thermique en espace ouvert', IBPSA France 2000 Modélisation et simulation des bâtiments Qualité environnementale des bâtiments et simulation, IBPSA, Sophia-Antipolis, France, pp. 29-35.

Voogt, J. A. and Oke, T. R.: 1997, 'Complete Urban Surface Temperatures', J. Appl. Meteorol. 36, 1117-1132.

Voogt, J. A. and Oke, T. R.: 1998, 'Effects of Surface Geometry on Remotely-Sensed Surface Temperature', Int. J. Remote Sens. 19, 895-920.

Walpersdorf, A., Bock, O., Doerflinger, E., Masson, F., Van Baelen, J., Somieski, A., and Bürki, B.: 2004, 'Data Analysis of a Dense GPS Network Operated during the ESCOMPTE Campaign: First Results', Phys. Chem. Earth 29, 201-211. 